NBER WORKING PAPER SERIES

\title{
FINANCIAL SAFETY NETS
}

\author{
Julien Bengui \\ Javier Bianchi \\ Louphou Coulibaly
}

Working Paper 22594

http://www.nber.org/papers/w22594

\author{
NATIONAL BUREAU OF ECONOMIC RESEARCH \\ 1050 Massachusetts Avenue \\ Cambridge, MA 02138 \\ September 2016, Revised October 2017
}

For useful comments and suggestions, we thank Rui Castro, Doug Diamond, Kinda Hachem, Baris Kaymak, Pierre Yared (editor), two anonymous referees, as well as seminar participants at the University of Chicago Booth School of Business and the 2016 SED Annual Meeting. The views expressed herein are those of the authors and not necessarily those of the Federal Reserve Bank of Minneapolis, the Federal Reserve System, or the National Bureau of Economic Research.

NBER working papers are circulated for discussion and comment purposes. They have not been peer-reviewed or been subject to the review by the NBER Board of Directors that accompanies official NBER publications.

(C) 2016 by Julien Bengui, Javier Bianchi, and Louphou Coulibaly. All rights reserved. Short sections of text, not to exceed two paragraphs, may be quoted without explicit permission provided that full credit, including $\odot$ notice, is given to the source. 
Financial Safety Nets

Julien Bengui, Javier Bianchi, and Louphou Coulibaly

NBER Working Paper No. 22594

September 2016, Revised October 2017

JEL No. E58,E61,G28

\section{$\underline{\text { ABSTRACT }}$}

In this paper, we study the optimal design of financial safety nets under limited private credit. We ask when it is optimal to restrict ex ante the set of investors that can receive public liquidity support ex post. When the government can commit, the optimal safety net covers all investors. Introducing a wedge between identical investors is inefficient. Without commitment, an optimally designed financial safety net covers only a subset of investors. Compared to an economy where all investors are protected, this results in more liquid portfolios, better social insurance, and higher ex ante welfare. Our result can rationalize the prevalent limited coverage of safety nets, such as the lender of last resort facilities.

Julien Bengui

Département de sciences économiques

Université de Montréal

C.P. 6128, succursale Centre-ville

Montréal QC H3C 3J7

Canada

julien.bengui@umontreal.ca

Javier Bianchi

Federal Reserve Bank of Minneapolis

90 Hennepin Avenue

Minneapolis, MN 55401

and NBER

javieribianchi@gmail.com
Louphou Coulibaly

Département de sciences économiques

Université de Montréal

C.P. 6128, succursale Centre-ville

Montréal QC H3C 3J7

Canada

c.louphou@gmail.com 


\section{Introduction}

Safety nets are a central pillar of modern financial architectures. By granting liquidity support to a collection of institutions, a safety net can relieve the strains of eligible members in financial distress. A long-standing concern about safety nets, however, is that they can lead to excessive risk taking. ${ }^{1}$ Accordingly, a key question regarding the design of safety nets is: How should the stability gained from a financial safety net be balanced against the moral hazard problem? Despite extensive discussions, the literature lacks a theoretical framework that can be used to address this question.

In this paper, we tackle the design of financial safety nets using a stylized model of liquidity demand under limited private credit. As in Holmström and Tirole (1998), the government can relax credit constraints by providing public liquidity. The question we address is whether the government should restrict ex ante the set of investors to whom it provides liquidity support ex post. In a nutshell, how wide should the financial safety net be?

The importance of defining the scope of financial safety nets was underscored during the 2008 financial crisis, especially surrounding the run on the shadow banking system. Because only depository institutions are granted access to discount window facilities, the Federal Reserve found it challenging to provide a backstop to those non-depository institutions in financial distress. Invoking legal constraints, the US Treasury and the Federal Reserve let Lehman Brothers fail, despite mounting pressures to provide a rescue package. ${ }^{2}$ At the time, many observers interpreted the failure to rescue Lehman as a manifestation of a line in the sand between depository institutions and shadow banks, or, through the lens of our model, a definition of the scope of the safety net. ${ }^{3}$

We study a model in which investors can save in short-term and long-term assets. These investors are subject to private idiosyncratic liquidity shocks, which occur before the long-term asset's payoffs are realized, as in Diamond and Dybvig (1983). Because private contracts are not enforceable, this limits borrowing to smooth liquidity shocks, and in turn introduces a role for public liquidity provision. The government issues bonds to finance liquidity facilities, and investors can anonymously trade these bonds. The new feature we introduce in this model is a government's choice about the share of investors that are eligible for public liquidity support. Specifically, we consider a government that chooses at time 0 the share of investors that will be

\footnotetext{
${ }^{1}$ Greenspan (2001) notably warned that policymakers must be "very cautious about purposefully or inadvertently extending the scope and reach of the safety net."

${ }^{2}$ In his testimony at the Financial Crisis Inquiry Commission in 2009, then Chairman Ben Bernanke stated: "I will maintain to my deathbed that we made every effort to save Lehman, but we were just unable to do so because of a lack of legal authority."

${ }^{3}$ Other examples of safety nets arise naturally in international credit markets, involving, for example, the IMF or other multilateral organizations.
} 
eligible for liquidity support in the interim period, and lacks commitment to the magnitude of the liquidity support provided to each eligible investor. The assumption that the government can commit to the safety net captures in a stylized manner that once a safety net is defined, it is more difficult for the government to bypass the scope of the safety net ex post, as vividly illustrated by the example of Lehman's bankruptcy. We label the set of investors eligible for ex post public support the protected sphere and the set of investors excluded from it the unprotected sphere. Having access to a public liquidity facility, protected agents choose higher yield, longer-term portfolios than unprotected agents, who have to rely on the short-term asset to self-insure.

Our analysis of financial safety nets delivers several results, on both the positive and normative fronts. We first show that if the government can commit to a future liquidity provision policy, the optimal safety net covers the entire set of investors. With commitment, the government can provide an amount of public liquidity that induces the efficient amount of investment in long-term assets and thereby leads to the efficient allocation. ${ }^{4}$ Offering a differential treatment to identical investors is inefficient if the government has commitment. In this case, the optimal size of the unprotected sphere is zero.

We then consider the optimal safety net when the government lacks commitment. Specifically, we study a time-consistent equilibrium in which the government chooses without commitment the liquidity support in the interim period. We can characterize in closed form three distinct regions depending on how wide the safety net is (i.e., how large is the protected sphere chosen by the government at time 0). In an economy with a small protected sphere, only a small subset of agents invest in the higher yield, long-term asset, resulting in low output. With few agents accessing the liquidity facilities, this results in a low level of public debt and a low interest rate. A low interest rate benefits protected agents because it reduces the cost of accessing liquidity facilities in the event of a liquidity shock. Conversely, unprotected agents who save in the short-term assets are hurt by the low return on their savings. As a result, there is a large welfare gap between protected and unprotected agents. An economy with a larger protected sphere features more agents investing in the higher yield, long-term asset and therefore higher output. In turn, because many agents resort to liquidity facilities, this leads to a higher level of public debt and a high interest rate, which reduces the welfare gap between protected and unprotected agents.

Our main normative result is that in a time-consistent equilibrium, the optimal ex ante government's choice implies an intermediate-size protected sphere. Unlike in the commitment case, it is optimal to leave a fraction of investors, strictly between 0 and 1 , without liquidity

\footnotetext{
${ }^{4}$ As in Yared (2013), the amount of liquidity provision under commitment induces a wedge between the technological rate of return on the long asset and the rate of return on government bonds.
} 
support. A safety net covering all investors is undesirable because, under lack of commitment, the government provides too much liquidity support to protected investors ex post. Anticipating an access to public liquidity facilities, protected investors free ride on others' investment in short-term assets and choose excessively illiquid portfolios. In order to finance the liquidity facilities, the government needs to issue a large amount of public debt. This in turn yields an interest rate on government bonds that is too high from a social point of view. A high interest rate redistributes resources away from investors that have liquidity shortfalls and hurts ex ante welfare. Because of incomplete markets, the costs of this higher interest rate for borrowing investors that have a shortfall of liquidity outweigh the benefits to lending investors that have a surplus of liquidity. In addition, a midsize protected sphere also dominates a small protected sphere because it features less socially costly liquidity hoarding. A safety net with a midsize protected sphere is thus desirable from an ex ante welfare perspective.

Related literature This paper is related to a vast literature on public liquidity provision. Woodford (1990) and Holmström and Tirole (1998) are classic papers showing how public liquidity provision may relax private borrowing limits. In our model, the government also has a special role as a liquidity provider, but we address a distinct issue - the design of financial safety nets. In particular, our model rationalizes a key feature of prevailing safety nets, where some financial institutions have access to a discount window while other institutions performing essentially the same activities do not.

Jacklin (1987) argues that full trading opportunities in the Diamond and Dybvig model generates a free-rider problem that leads to an inefficient equalization of the marginal rate of transformation and the interest rate. Farhi, Golosov and Tsyvinski (2009) study a mechanism design problem and show how liquidity regulation can achieve a constrained efficient outcome in this context. In Grochulski and Zhang (2015), the ability of banks to bypass liquidity regulation puts an additional constraint on the mechanism design problem, and reduces the magnitude of the intervention. We abstract from liquidity regulation and focus instead on public liquidity provision and the design of the safety net.

Our environment is closest to Yared (2013). He studies optimal liquidity provision under commitment, and shows that it entails a wedge between the technological rate of return on the long asset and the rate of return on government bonds. The government restricts transfers and bond issuances, so that the return on government bonds remains low, which leads to superior risk sharing. ${ }^{5}$ We study instead optimal liquidity provision policy when the government lacks commitment. In particular, we show that the government provides too much liquidity ex

\footnotetext{
${ }^{5}$ In a different environment, Yared (2015) and Bhandari, Evans, Golosov and Sargent (2015) study the effects of government debt on inequality.
} 
post for investors within the safety net, and hence the optimal liquidity provision plan under commitment is not implementable. We characterize aggregate investment and risk sharing as a function of the size of the safety net and show that it is strictly optimal to leave a share of investors outside the safety net.

A related literature highlights how bailouts can increase financial fragility when the government lacks commitment. Farhi and Tirole (2012) show that discretionary interest rate policy makes private leverage decisions strategic complements and generates multiple equilibria. Lack of commitment also plays an important role in the analysis of bailouts by Acharya and Yorulmazer (2007), Diamond and Rajan (2012), and Chari and Kehoe (20016). Nosal and Ordoñez (2016) show that a government's uncertainty about whether failed institutions were affected by idiosyncratic or systemic shocks creates strategic restraint in leverage decisions and supports government commitment. Freixas (1999) shows that randomizing between bailing out banks in distress or not can create "constructive ambiguity" and reduce risk taking. Keister (2016) presents an environment in which a commitment to a no bailout policy is undesirable because it can increase the likelihood of bank runs, and Keister and Narasiman (2016) show that these policy conclusions emerge regardless of whether bank runs are driven by expectations or fundamentals. Bianchi (2016) finds that bailouts are desirable despite the moral hazard effects if conducted only during systemic crises. None of these papers, however, study the optimal design of financial safety nets.

Our paper also relates to a growing literature on shadow banking. Existing work emphasizes regulatory arbitrage as the raison d'être of shadow banks (see, for instance, Acharya, Schnabl and Suarez (2013); Gorton and Metrick (2012); and Pozsar et al. (2010)). In this spirit, Plantin (2015) develops a model in which capital requirements lead banks to bypass regulation through a shadow banking sector. Ordoñez (2013) shows that the bluntness of capital requirements can make shadow banks desirable as a way to build reputation and better align the interests of banks and bondholders. In contrast, our analysis shows that the very existence of these institutions could be the result of the optimal plan of a government that is subject to a classic time-inconsistency problem.

The paper proceeds as follows. Section 2 describes the model. Section 3 describes the main results, and Section 4 concludes. The Appendix includes all of the proofs. 


\section{The Model}

\subsection{Technology and Preferences}

The environment is based on the Diamond and Dybvig (1983) model of consumer liquidity demand that has been a workhorse in the study of financial intermediation. It is closest to the model presented by Yared (2013). The economy lasts for three dates: $t=0,1,2$. There is a single consumption good and there are two technologies, which we label the short asset and the long asset. The short asset pays one unit of the good at $t+1$ for each unit invested at $t$. The long asset pays $\hat{R}>1$ units at date 2 for each unit invested at date 0 . For simplicity, we assume that the long asset cannot be liquidated at date $1 .^{6}$

The economy is populated by a unit continuum of ex-ante identical agents. These agents are endowed with $e$ units of the good at $t=0$. The type space has two dimensions. At date 0 , each individual draws the first dimension of his type: $s=\{P, U\}$. A fraction $\gamma \in[0,1]$ of individuals is of type $s=P$, and the complementary fraction $1-\gamma$ is of type $s=U$. $P$ stands for protected, while $U$ stands for unprotected. As we will explain below, protected agents have access to public liquidity and unprotected agents do not. The type dimension $s$ is public information, and the parameter $\gamma$ is a policy choice on which we elaborate more in Section 2.2. At date 1 , an agent draws the second dimension of his type, $\theta=\{0,1\}$, which determines the preference for early consumption. With probability $\pi \in(0,1)$, an individual is of type $\theta=0$, while with probability $1-\pi$, he is of type $\theta=1$. The distribution parameter $\pi$ is a fundamental of the economy. Agents have Diamond-Dybvig preferences: the utility of an individual of type $(s, \theta)$ is given by

$$
U\left(c_{1}^{s}, c_{2}^{s}, \theta\right)=(1-\theta) u\left(c_{1}^{s}\right)+\theta \rho u\left(c_{1}^{s}+c_{2}^{s}\right)
$$

where $c_{1}^{s}$ and $c_{2}^{s}$ represent the respective date 1 and date 2 consumption levels, while $\rho$ is a discount factor. The utility function $u(\cdot)$ is twice continuously differentiable, strictly increasing, and strictly concave, and satisfies the Inada conditions $\lim _{c \rightarrow 0} u^{\prime}(c)=\infty$ and $\lim _{c \rightarrow \infty} u^{\prime}(c)=0$.

The type dimension $\theta$ refers to liquidity shocks. Agents of type $\theta=0$ are hit by liquidity shocks and only value consumption at date 1 , whereas agents of type $\theta=1$ are not hit by liquidity shocks and are indifferent between consumption at date 1 and date 2. As is standard in the literature, we assume that the type dimension $\theta$ is private and cannot be observed by other agents or the government. We will often refer to agents hit by a liquidity shock as impatient agents and to agents not hit by a liquidity shock as patient agents.

The type dimension $s$ determines the eligibility for public support at $t=1$. Agents of type $s=U$ are unprotected and are not entitled to public liquidity provision, whereas agents of type

\footnotetext{
${ }^{6}$ All results carry through qualitatively as long as the date 1 liquidation value is strictly smaller than one.
} 
$s=P$ are protected and can receive public liquidity at date 1 . Unlike the type dimension $\theta$, the type dimension $s$ is public. In what follows, we will denote an allocation of consumption across consumers by $\left\{c_{1}^{s}(\theta), c_{2}^{s}(\theta)\right\}_{\theta \in\{0,1\}, s \in\{U, P\}}$.

We define $\ell^{s} \in[0,1]$ as the fraction of the date 0 endowment invested in the short asset by a type $s$ individual. Accordingly, we denote by $L^{s} \in[0,1]$ the aggregate choice of type $s$ individuals. In equilibrium, consistency will require that aggregate and individual choices coincide, that is, $L^{s}=\ell^{s}$ for $s \in\{U, P\}$.

We make some parametric assumptions to ensure that the equilibria we consider fall within economically interesting regions.

Assumption 1. As in Diamond and Dybvig (1983), the relative risk aversion is weakly larger than 1:

$$
-\frac{u^{\prime}(c)}{c u^{\prime \prime}(c)} \leq 1 \quad \text { for all } \quad c>0
$$

and $\hat{R}^{-1}<\rho<1$.

Assumption 1 notably implies that efficient risk sharing requires impatient agents to consume more than $e$ and patient agents to consume less than $\hat{R} e$.

Assumption 2. The probability of being hit by a liquidity shock is not too small:

$$
\pi \geq \frac{\rho(\hat{R}-1)}{1+\rho(\hat{R}-1)} .
$$

This assumption ensures that in all equilibria we consider, agents make investment choices such that they never consume positive amounts at date 2 when they turn out to be impatient. ${ }^{7}$

\subsection{Public Liquidity Provision and Markets}

We assume that private contracts are not enforceable. The assumption of unobservability of liquidity shocks implies that contracts cannot be written at date 0 contingent upon their realization at date 1 , and the lack of enforceability implies that agents cannot borrow privately either at date 0 or at date 1 . The assumption of imperfect private contract enforceability motivates the analysis of public liquidity provision and the design of an optimal safety net.

The government makes two distinct choices at date 0 and date 1 . At date 0 , it sets the share of protected agents $\gamma$, and hence sets the respective probabilities with which an agent draws a

\footnotetext{
${ }^{7}$ Agents who turn out to be impatient do not value date 2 consumption, but if liquidity shocks occur with a sufficiently low probability, they might find it optimal to make investment decisions at date 0 that result in an ex post wasting of date 2 resources in the contingency where they are hit by these shocks. Assumption 2 rules out this case.
} 
type $s=U$ or $s=P$ at date 0 . At date 1 , it provides a liquidity facility to protected agents, and finances it by issuing public debt. We hereafter provide details on the government's policy at date 1 and postpone our exposition of the government's date 0 safety net decision to Section 3.

At date 1, the government issues public debt and extends credit to protected agents. At date 2 , it uses the proceeds from protected private investors' repayments to pay back public debt holders. In the background, we assume that the government has a superior technology to enforce repayment, which is a standard assumption in the literature on public liquidity provision. As we will show below, this access to a better enforcement technology allows the government to reach the efficient allocations under commitment, but not under discretion.

We assume that the credit facility is contingent on protected agents' portfolio position. ${ }^{8}$ Because the liquidity shock realization is private information, the credit facility cannot be made contingent on $\theta$. Accordingly, we denote the quantity of credit extended by the government to agents with short asset position $\ell$ by $B(\ell)$ and the aggregate amount of public debt by $\mathcal{B}$. The government demands the same interest rate $1 / q$ on the credit it extends to protected agents as the one it pays on its own public debt, it has zero initial public debt, and it does not finance any public expenditures. Its budget constraints thus require that

$$
\int_{0}^{\gamma} B\left(\ell_{j}\right) d j=\mathcal{B} .
$$

We denote by $b^{s}(\theta)$ the individual holdings of government bonds and assume that government bonds cannot be shortened (i.e., $b^{s}(\theta) \geq 0$ ). The budget constraints of an unprotected agent are represented by

$$
\begin{aligned}
\ell^{U} & \in[0,1] \\
c_{1}^{U}(\theta) & =\ell^{U} e-q b^{U}(\theta), \\
c_{2}^{U}(\theta) & =\hat{R}\left(1-\ell^{U}\right) e+b^{U}(\theta),
\end{aligned}
$$

while those of a protected agent are represented by

$$
\begin{aligned}
\ell^{P} & \in[0,1], \\
c_{1}^{P}(\theta) & =\ell^{P} e-q b^{P}(\theta)+q B\left(\ell^{P}\right), \\
c_{2}^{P}(\theta) & =\hat{R}\left(1-\ell^{P}\right) e+b^{P}(\theta)-B\left(\ell^{P}\right),
\end{aligned}
$$

\footnotetext{
${ }^{8}$ By making the government liquidity provision contingent on individual variables as opposed to aggregate variables, we are able to abstract from issues of multiplicity that would arise in this model when we turn to the optimal time-consistent equilibria (see, e.g., Farhi and Tirole, 2012).
} 
for $\theta \in\{0,1\}$. We have used in (5) and (8) that in an equilibrium with $q \leq 1$, agents weakly prefer to save using government bonds between date 1 and date 2 rather than use the short asset. ${ }^{9}$ Combining the government's budget constraint (3) with (5), (6), (8), (9) and the public debt market clearing condition

$$
\mathcal{B}=(1-\gamma)\left[\pi b^{U}(0)+(1-\pi) b^{U}(1)\right]+\gamma\left[\pi b^{P}(0)+(1-\pi) b^{P}(1)\right]
$$

we obtain that a feasible allocation needs to satisfy the economy's resource constraint

$$
\begin{aligned}
& \pi\left[(1-\gamma)\left(c_{1}^{U}(0)+\frac{c_{2}^{U}(0)}{\hat{R}}\right)+\gamma\left(c_{1}^{P}(0)+\frac{c_{2}^{P}(0)}{\hat{R}}\right)\right] \\
& +(1-\pi)\left[(1-\gamma)\left(c_{1}^{U}(1)+\frac{c_{2}^{U}(1)}{\hat{R}}\right)+\gamma\left(c_{1}^{P}(1)+\frac{c_{2}^{P}(1)}{\hat{R}}\right)\right]=e .
\end{aligned}
$$

An alternative representation of the agents' constraint set is given by

$$
\begin{aligned}
c_{1}^{s}(\theta)+q c_{2}^{s}(\theta) & =\ell^{s} e+q \hat{R}\left(1-\ell^{s}\right) e \\
c_{1}^{s}(\theta) & \leq \ell^{s} e+\mathbb{I}_{\{s=P\}} q B\left(\ell^{s}\right) .
\end{aligned}
$$

These substitutions show that the protected agent's problem induced by a government debt policy is equivalent to that of an agent who faces an exogenous borrowing limit $b^{P}(\theta) \geq-B\left(\ell^{P}\right)$ in the absence of public liquidity provision. On the other hand, because they do not benefit from public liquidity provision, unprotected agents always face an effective borrowing limit $b^{U}(\theta) \geq 0$. The government's date 0 choice about the size of the protected sphere will determine the respective fractions of agents facing a relaxed borrowing limit $-B(\ell)$ and of those facing an unrelaxed limit at 0 . One might think that the government would like to maximize the fraction of agents who face a relaxed borrowing limit ex post, but as our analysis of Section 3 reveals, this not the case when the government cannot commit ex ante about its debt issuance policy. The timeline is summarized in Figure 1.

We let $(s, \ell, \theta)$ denote an agent's individual state and $X \equiv\left(\gamma, L^{U}, L^{P}\right)$ denote the aggregate state. We also let $B(\ell)$ denote a public liquidity provision policy, $q(X)$ denote the bond pricing function, and $\mathcal{C}_{1}(s, \ell, \theta, X), \mathcal{C}_{2}(s, \ell, \theta, X)$ represent the date 1 decision rules of an agent, whose

\footnotetext{
${ }^{9}$ An equilibrium with $q>1$ implies $b^{s}(\theta)=0$. That is, if the return on government bonds is lower than the return on short assets, government bonds would be strictly dominated assets.
} 
Gov. chooses

share of protected agents
Gov. provides liquidity Gov. collects repayments to protected agents from protected agents

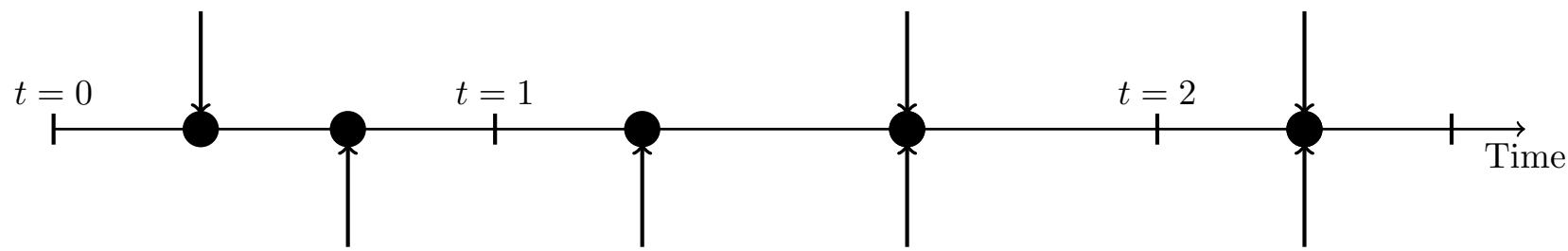

Agents observe their public type $s$ and invest
Agents observe their private type $\theta$
Agents invest and consume
Agents collect investment proceeds and consume

Figure 1: Timeline of the model.

problem is

$$
\mathcal{V}_{1}(s, \ell, \theta, X)=\max _{c_{1}, c_{2}} U\left(c_{1}, c_{2}, \theta\right)
$$

subject to

$$
c_{1}+q(X) c_{2}=\ell e+q(X) \hat{R}(1-\ell) e, \quad \text { and } \quad c_{1} \leq \ell e+\kappa(s, \ell, X),
$$

where

$$
\kappa(s, \ell, X) \equiv \begin{cases}0 & \text { for } s=U \\ q(X) B(\ell) & \text { for } s=P\end{cases}
$$

is a type- and agent-specific effective borrowing limit. This problem is defined for any policy $B(\ell)$. We can then define a date 1 continuation equilibrium.

Definition 1 (Continuation equilibrium). Given a government policy $B(\ell)$, a continuation equilibrium is a value function $\mathcal{V}_{1}(s, \ell, \theta, X)$ with associated decision rules $\mathcal{C}_{1}(s, \ell, \theta, X), \mathcal{C}_{2}(s, \ell, \theta, X)$, and $a$ bond pricing function $q(X)$ such that

1. given $q(X)$ and $B(\ell), \mathcal{V}_{1}(s, \ell, \theta, X)$ solves the agent's date 1 problem (12), and

2. the markets for date 1 and 2 consumption clear: ${ }^{10}$

$$
\begin{aligned}
\sum_{s} \sum_{\theta} \gamma_{s} \pi_{\theta} \mathcal{C}_{1}\left(s, L^{s}, \theta, X\right) \leq & \sum_{s} \gamma_{s} L^{s} e \\
\sum_{s} \sum_{\theta} \gamma_{s} \pi_{\theta} \mathcal{C}_{2}\left(s, L^{s}, \theta, X\right)= & \sum_{s} \gamma_{s} \hat{R}\left(1-L^{s}\right) e \\
& +\left[\sum_{s} \gamma_{s} L^{s} e-\sum_{s} \sum_{\theta} \gamma_{s} \pi_{\theta} \mathcal{C}_{1}\left(s, L^{s}, \theta, X\right)\right] .
\end{aligned}
$$

${ }^{10}$ To simplify notation, we define $\pi_{0} \equiv \pi$ and $\pi_{1} \equiv 1-\pi$, as well as $\gamma_{P} \equiv \gamma$ and $\gamma_{U} \equiv 1-\gamma$. 
This is a standard definition of a competitive equilibrium, adapted to accommodate the dependence of the government's liquidity provision policy upon the ex-ante choices of agents. Condition (14) requires that aggregate date 1 consumption does not exceed the aggregate payoff of the short asset at date 1 . Condition (15) requires that aggregate date 2 consumption does not exceed the aggregate payoff of the long asset, plus the payoff of the short asset invested in between date 1 and date 2. By Walras' law, the market clearing condition on government bonds is satisfied. The following lemma characterizes a continuation equilibrium. This characterization will be useful when we turn to analyze the optimal government policy and highlight the role of commitment.

Lemma 1 (Continuation equilibrium). A continuation equilibrium features ${ }^{11}$

1. a bond price function satisfying

$$
q(X)=\min \left\{e \frac{1-\pi}{\pi} \frac{\gamma L^{P}+(1-\gamma) L^{U}}{\gamma \min \left\{\hat{R}\left(1-L^{P}\right) e, B\left(L^{P}\right)\right\}}, 1\right\},
$$

2. consumption allocations satisfying

$$
\begin{aligned}
& \mathcal{C}_{1}(s, \ell, 0, X)=\ell e+\min \{q(X) \hat{R}(1-\ell) e, \kappa(s, \ell, X)\}, \\
& \mathcal{C}_{2}(s, \ell, 0, X)=\max \left\{\hat{R}(1-\ell) e-\frac{\kappa(s, \ell, X)}{q(X)}, 0\right\}, \\
& \mathcal{C}_{1}(s, \ell, 1, X)=0, \\
& \mathcal{C}_{2}(s, \ell, 1, X)=\hat{R}(1-\ell) e+\frac{\ell e}{q(X)} .
\end{aligned}
$$

Proof. See Appendix A.1.

According to this lemma, in the absence of public liquidity provision, all impatient agents consume the proceeds of their short asset at date 1 and consume the payoff of their long asset at date 2 . The latter is wasteful because these agents do not value date 2 consumption, but they have no choice since credit constraints prevent them from transferring resources from date 2 to date 1. By relaxing protected agents' effective credit constraint, the extension of public liquidity allows this set of agents to transfer some or all of their date 2 illiquid wealth stemming from the payoff of their long asset back into date 1. Patient agents, on the other hand, consume only at date 2 . These agents are natural savers at date 1 , and therefore public debt issuance does not

\footnotetext{
${ }^{11}$ When an equilibrium features $q=1$, any other allocation such that $c_{1}+c_{2}=\hat{R}(1-\ell) e+\ell e\left(\right.$ and $\left.c_{1}, c_{2} \geq 0\right)$, together with the price $q=1$, also constitutes an equilibrium, but we can focus without loss of generality on the one featuring $c_{1}=0$ and $c_{2}=\hat{R}(1-\ell) e+\ell e$.
} 
generate an asymmetry between the protected and unprotected patient agents' consumption. However, patient agents (at least weakly) benefit from a higher level of public debt to the extent that it (weakly) increases the interest rate they earn on date 1 bond purchases (the bond price $q$ is weakly decreasing in public debt issuance $\mathcal{B}$ since the demand for government bonds by patient agents is decreasing in the price).

For a given liquidity provision policy $B(\ell)$, an agent's date 0 problem can be represented as

$$
\mathcal{V}_{0}(s, X)=\max _{\ell \in[0,1]} \pi \mathcal{V}_{1}(s, \ell, 0, X)+(1-\pi) \mathcal{V}_{1}(s, \ell, 1, X)
$$

Given this date 0 problem and Definition 1 of a continuation equilibrium, we have the following definition of a competitive equilibrium:

Definition 2 (Competitive equilibrium). Given government policies $\{\gamma, B(\ell), \mathcal{B}\}$, a competitive equilibrium is a vector of aggregate variables $X$, a date 0 value function $\mathcal{V}_{0}(s, X)$ with associated policy function $\ell(s, X)$, a date 1 value function $\mathcal{V}_{1}(s, \ell, \theta, X)$ with associated decision rules $\mathcal{C}_{1}(s, \ell, \theta, X), \mathcal{C}_{2}(s, \ell, \theta, X)$, and a bond price function $q(X)$ such that

1. $\mathcal{V}_{1}(s, \ell, \theta, X), \mathcal{C}_{1}(s, \ell, \theta, X), \mathcal{C}_{2}(s, \ell, \theta, X)$, and $q(X)$ are induced by a continuation equilibrium according to Definition 1 ,

2. $\mathcal{V}_{0}(s, X), \ell(s, X)$ solve the agent's problem (21),

3. aggregate variables are consistent with individual choices: $X=(\gamma, \ell(P, X), \ell(U, X))$,

4. the government's budget constraint (3) is satisfied.

Discussion of assumptions. Before we turn to the normative analysis of safety nets, it is useful to discuss some assumptions we have made. A first set of assumptions regard the imperfect enforceability of private contracts, which are standard in the literature to motivate a role for public liquidity provision. We also assume that there is no private credit market at either date 0 or date 1 , and that there are no secondary markets for long assets in the interim period. $^{12}$ Both of these assumptions can be relaxed to some extent, as discussed in Section 3.3.4. As long as the constraints on either borrowing or sales of assets are sufficiently tight, our qualitative results remain unchanged.

\footnotetext{
12 Allowing for a secondary market for assets is equivalent to allowing for private credit markets. The basic idea is that a patient investor would buy the assets from an impatient investor, in the same way as a patient investor would lend to an impatient investor in the credit market. A standard argument for restrictions on secondary markets is asymmetric information. If the quality of the asset cannot be verified by the buyer, the market could break down or restrictions could be imposed on the amount of assets that can be sold (e.g., Akerlof (1970); Kiyotaki and Moore, 2012).
} 
Our second set of assumptions regard our modeling of safety nets. We assume that the government can credibly commit to excluding a set of investors from financial assistance. In line with our motivation, we are interested in developing an environment in which the government is able to implement such a policy. In the background, we want to capture a variety of situations in which explicitly defining a safety net makes it more difficult for the government to rescue ex post those institutions that are not eligible to receive assistance. While in practice there are certainly circumstances under which the government bypasses the scope of the safety net defined earlier in time, doing so brings up reputational costs for the government. ${ }^{13}$ Incorporating these reputational costs would require a dynamic environment, which is beyond the scope of this paper. Still, Section 3.3.4 shows that when investors anticipate that the safety net announced by the government will be implemented, the government does not find it optimal to deviate from the announcement ex post.

In addition, we also assume that investors have no choice regarding which sphere they belong to. The government chooses the size of the protected and unprotected spheres, and investors are assigned randomly to either of the two spheres. As it will turn out, the equilibrium welfare of protected investors will be higher than that of unprotected investors. A potentially interesting issue that we abstract from is investors' entry decision into the two spheres in the presence of other costs associated with being in the protected sphere (e.g., there could be a tax on protected investors so that in equilibrium, investors are indifferent between belonging to either of the two spheres). ${ }^{14}$

\section{Optimal Policy Analysis}

\subsection{Efficient Allocation}

We start by characterizing the efficient allocation. This allocation will serve as a benchmark for our normative analysis. In presenting this allocation, we abstract from the type dimension $s$ of agents, since it is unrelated to their preferences. The efficient allocation solves the following

\footnotetext{
${ }^{13}$ For example, the Federal Reserve ended up providing emergency liquidity assistance to non-depository primary dealers, through programs such as the Primary Dealer Credit Facility (PDCF) and the Term Securities Lending Facility (TSLF).

${ }^{14}$ In an interesting paper, Grochulski and Zhang (2015) analyze optimal regulation in an environment in which banks can choose to shift activity to an unregulated sector to avoid liquidity regulation by incurring an exogenous cost. One possible foundation for this cost could be a loss of safety net coverage associated with shifting activity away from the regulated sector that we model in this paper.
} 
problem:

$$
\max _{c_{1}(0), c_{2}(0), c_{1}(1), c_{1}(2)} \pi U\left(c_{1}(0), c_{2}(0), 0\right)+(1-\pi) U\left(c_{1}(1), c_{2}(1), 1\right)
$$

subject to

$$
\pi\left[c_{1}(0)+\frac{c_{2}(0)}{\hat{R}}\right]+(1-\pi)\left[c_{1}(1)+\frac{c_{2}(1)}{\hat{R}}\right] \leq e
$$

and $c_{1}(0), c_{2}(0), c_{1}(1), c_{2}(1) \geq 0$.

The solution to this problem is described in the lemma below.

Lemma 2 (Efficient Allocation). The solution to the planning problem satisfies $e<c_{1}^{*}(0)<$ $c_{2}^{*}(1)<\hat{R} e$ and $c_{2}^{*}(0)=c_{1}^{*}(1)=0$, with $u^{\prime}\left(c_{1}^{*}(0)\right)=\rho \hat{R} u^{\prime}\left(c_{2}^{*}(1)\right)$.

Proof. See Appendix A.2.

Thus, as is standard under Diamond-Dybvig preferences, the allocation features zero date 2 consumption of impatient agents, zero date 1 consumption of patient agents, and risk sharing between patient and impatient agents that is consistent with an equalization of the social marginal rate of transformation $1 / \hat{R}$ and the marginal rate of substitution $\rho u^{\prime}\left(c_{2}^{*}(1)\right) / u^{\prime}\left(c_{1}^{*}(0)\right)$.

\subsection{Optimal Safety Net under Commitment}

We now turn to analyzing decentralized equilibria. We start by assuming that the government can commit at date 0 about its date 1 liquidity provision policy. This will be helpful to highlight the role of the government's inability to commit in our analysis of the design of the optimal safety net.

In this case, after the government sets $\gamma$ and credibly announces a future liquidity provision policy $B^{c}(\ell)$ at date 0 , private agents make investment choices. Recall that agents know whether they are protected at the time of making their date 0 investment choice. As discussed earlier, households draw their type randomly and thus cannot choose to become protected or unprotected.

Under commitment, the government chooses the policy $\left\{\gamma^{c}, B^{c}(\ell), \mathcal{B}^{c}\right\}$ to attain the competitive equilibrium with highest time 0 utility.

Proposition 1 (Optimal policy under commitment). A safety net architecture covering all agents $\left(\gamma^{c}=1\right)$, together with a commitment to provide an amount of public liquidity $B^{c}(\ell)=$ $B^{c}=(1-\pi) c_{2}^{*}(1)$, achieves the efficient allocation described in Lemma 2.

Proof. See Appendix A.3. 
This proposition shows that it is optimal to cover all agents and that the appropriate amount of liquidity provision achieves the efficient allocations. The latter result is related to Yared (2013), who established that under a weaker version of Assumption 2, a fiscal policy scheme equivalent to our credit facility can achieve the efficient allocations when the government has commitment. ${ }^{15}$ Proposition 1 indicates that if the government were able to commit to a future liquidity provision policy, it would not leave any agent outside the safety net. In fact, setting a boundary between protected agents and unprotected agents not only is redundant but also would deliver strictly lower ex ante welfare. ${ }^{16}$

Below, we relax the assumption that the government can commit to its liquidity provision policy and show that having a smaller safety net becomes strictly optimal. To put the results below into perspective, it is useful to note that under commitment, the amount of liquidity provision that the government commits to provide puts a lower bound on the amount of short assets that agents choose to invest in. If agents were to invest less in short assets than the level associated with the efficient allocation and were to end up being impatient, they would become credit constrained. This will contrast with the outcome that prevails when the government lacks commitment. As we show below, under discretion the government will ex post relax agents' credit constraints unconditionally (i.e., for any values of their investment choice). Anticipating the reaction of the government, agents will invest too little in short assets in the initial period. The inability of the government to commit to the extent of an ex post public liquidity provision will create a rationale for optimal management of the safety net.

\subsection{Optimal Safety Net under Discretion}

To analyze optimal policy under discretion, we proceed by backward induction. We start by solving for the government's optimal liquidity provision policy at date 1 when it is not bound by past commitments. We then move back to date 0 choices and characterize timeconsistent equilibria, for a given safety net architecture represented by the value of $\gamma$. Finally, we characterize the optimal ex ante choice of $\gamma$.

\subsubsection{Ex post Policy: Liquidity Provision}

After date 0 choices have been made, the government chooses the liquidity provision policy rule $B^{d}(\ell)$ to maximize the average welfare of unprotected and protected agents subject to the

\footnotetext{
${ }^{15}$ Without this assumption, Yared (2013) finds that the government, despite not reaching the efficient allocation, should still restrict public debt issuances to prevent underinvestment in liquid assets.

${ }^{16}$ To see this, note that an unprotected impatient agent's consumption cannot exceed $e$, which is strictly lower than the impatient agents' consumption in the efficient allocation.
} 
private sector's date 1 response to its actions. The government solves

$$
\begin{aligned}
\max _{\left\{B_{j}\right\}_{j \in[0, \gamma]}} & \int_{0}^{\gamma}\left[\pi \mathcal{V}_{1}\left(P, \ell_{i}, 0, X\right)+(1-\pi) \mathcal{V}_{1}\left(P, \ell_{i}, 1, X\right)\right] d i \\
& +\int_{\gamma}^{1}\left[\pi \mathcal{V}_{1}\left(U, \ell_{i}, 0, X\right)+(1-\pi) \mathcal{V}_{1}\left(U, \ell_{i}, 1, X\right)\right] d i
\end{aligned}
$$

where $\mathcal{V}_{1}(\cdot)$ is given by our definition of a continuation equilibrium.

The following proposition establishes that an optimal ex post policy always features a full relaxation of impatient protected agents' effective borrowing constraints at date 1 .

Proposition 2 (Optimal ex post bailout). An equilibrium with an optimal ex post policy features a full relaxation of impatient protected agents' effective credit constraints, $B^{d}(\ell)=$ $\hat{R}(1-\ell)$. Further, the equilibrium bond price is given by

$$
q(X)=\min \left\{\frac{1}{\hat{R}} \frac{1-\pi}{\pi} \frac{\gamma L^{P}+(1-\gamma) L^{U}}{\gamma\left(1-L^{P}\right)}, 1\right\}
$$

and the equilibrium consumption of protected agents is given by

$$
\begin{aligned}
\mathcal{C}_{1}(P, \ell, 0, X) & =\ell e+q(X) \hat{R}(1-\ell) e \\
\mathcal{C}_{2}(P, \ell, 1, X) & =\hat{R}(1-\ell) e+\frac{\ell e}{q(X)}
\end{aligned}
$$

Proof. See Appendix A.4.

Proposition 2 establishes that it is always optimal for the government to provide an amount of public liquidity that makes a protected agent unconstrained in a date 1 continuation equilibrium. The intuition for the ex post optimality of fully relaxing constraints is as follows. For $B_{i}<\hat{R}\left(1-\ell_{i}\right) e$, increasing $B_{i}$ always increases the equilibrium consumption of some agent without decreasing the equilibrium consumption of another agent. To see this, we distinguish the situations in which $q=1$ from the ones in which $q<1$. When $q=1$, an increase in $B_{i}$ increases the equilibrium consumption of the protected impatient agent $i$ while leaving the equilibrium consumption of other agents unchanged. The increase in agent $i$ 's consumption is the result of a borrowing constraint relaxation at a locally unchanged interest rate. When $q<1$, on the other hand, an increase in $B_{i}$ increases the equilibrium consumption of all patient agents while leaving the equilibrium consumption of impatient agents unchanged. The increase in patient agents' consumption results from the upward pressure on the return on government debt from date 1 to date 2 (i.e., $q$ is decreasing in $B_{i}$ ). It follows that the government's value function is strictly increasing in $B_{i}$ for $B_{i}<\hat{R}\left(1-\ell_{i}\right) e$. For $B_{i} \geq \hat{R}\left(1-\ell_{i}\right) e$, on the other 
hand, equilibrium consumption allocations do not locally depend on $B_{i}$. It follows that the debt issuance policy $B^{d}(\ell)=\hat{R}(1-\ell) e$ is optimal.

A higher level of public liquidity provision is thus always desirable ex post up to the point where protected agents' effective credit constraints are fully relaxed. This is true for any level of private investment. In the absence of commitment, an optimal public liquidity provision policy hence works as insurance provided freely to protected agents. This contrasts with the optimal policy under commitment, which offers a limited amount of insurance. This extra layer of insurance present under discretion will distort ex ante incentives.

As we will see below, the moral hazard costs induced by discretion in public liquidity provision depend on the size of the protected sphere. In the next sections, we provide a sharp analytical characterization of this relationship and analyze the key trade-offs involved in the optimal setting of the size of the safety net.

\subsubsection{Time-Consistent Equilibrium}

After the government has set $\gamma$ at date 0 , private agents make investment choices. Agents know $\gamma$ and forecast aggregate actions $L^{P}, L^{U}$ to form beliefs about $q(X)$. They also rationally anticipate the ex post public liquidity provision policy rule $B^{d}(\ell)$. We can define a timeconsistent equilibrium as follows:

Definition 3 (Time-consistent equilibrium for given safety net $\gamma$ ). For a given $\gamma$, a timeconsistent equilibrium is a liquidity provision policy $B^{d}(\ell)$, a bond price $q(X)$, consumption policies $\mathcal{C}_{1}(s, \ell, \theta, X), \mathcal{C}_{2}(s, \ell, \theta, X)$ and investment portfolio $\ell$ such that:

1. $B^{d}(\ell)$ solves (23),

2. $\ell$ solves (21),

3. $\mathcal{V}_{1}(s, \ell, \theta, X), \mathcal{C}_{1}(s, \ell, \theta, X), \mathcal{C}_{2}(s, \ell, \theta, X), q(X)$, and $B^{d}(\ell)$ are a continuation equilibrium according to Definition 1.

Using Proposition 2's result that $B^{d}(\ell)=\hat{R}(1-\ell) e$, the time-consistent equilibrium for given $\gamma$ can be conveniently solved for in closed form, as summarized in the following proposition.

Proposition 3 (Characterization of time-consistent equilibria for given safety net $\gamma$ ). In a time-consistent equilibrium, unprotected agents always invest all of their endowment into the short asset: $L^{U}=1$. For other variables, we can distinguish between three mutually exclusive regions, characterized by boundaries $0<\underline{\gamma}<\bar{\gamma}<1$, with $\underline{\gamma} \equiv \frac{1-\pi}{1-\pi+\hat{R} \pi}$ and $\bar{\gamma} \equiv 1-\pi$ :

- Region $I(0 \leq \gamma<\underline{\gamma})$ : protected agents invest $L^{P}=0$, the date 1 bond price is $q=1$, and the consumption allocations are $c_{1}^{U}(0)=c_{2}^{U}(1)=e$ and $c_{1}^{P}(0)=c_{2}^{P}(1)=\hat{R} e$. 
- Region II $(\gamma \leq \gamma \leq \bar{\gamma})$ : protected agents invest $L^{P}=0$, the date 1 bond price is $q=$ $\frac{1}{\hat{R}} \frac{(1-\pi)(1-\gamma)}{\pi \gamma}$, and the consumption allocations are $c_{1}^{U}(0)=e, c_{2}^{U}(1)=\hat{R} \frac{\pi \gamma}{(1-\pi)(1-\gamma)} e, c_{1}^{P}(0)=$ $\frac{(1-\pi)(1-\gamma)}{\pi \gamma} e$, and $c_{2}^{P}(1)=\hat{R} e$.

- Region III $(\bar{\gamma}<\gamma \leq 1)$ : protected agents invest $L^{P}=\frac{\pi+\gamma-1}{\gamma}$, the date 1 bond price is $q=1 / \hat{R}$, and the consumption allocations are $c_{1}^{U}(0)=c_{1}^{P}(0)=e$ and $c_{2}^{U}(1)=c_{2}^{P}(1)=\hat{R} e$.

Proof. See Appendix A.5.

The equilibrium of the model takes different forms depending on the size of the protected sphere $\gamma$. In all of the cases that arise, unprotected agents always invest all of their endowment in the short asset at date 0 . We note that in the laissez-faire benchmark where all agents are unprotected $(\gamma=0)$, everyone invests his entire endowment into the short asset $\left(L^{U}=1\right)$ and consumes an amount equal to that endowment whether hit by a liquidity shock or not at date $1\left(c^{U}(0)=c^{U}(1)=e\right)$. Thus, the laissez-faire benchmark features an extreme form of self-insurance that results in clear efficiency losses relative to the efficient allocation. We now discuss equilibrium properties in the different regions.

Region I When the fraction of protected agents is smaller than a threshold $\gamma<\frac{1-\pi}{1-\pi+\hat{R} \pi}$, we say that there is a small protected sphere. In this case, the demand for government bonds by patient unprotected agents at date 1 is large enough to push the interest rate down to its lower bound $1 / q=1$. In this region, impatient protected agents benefit from fully relaxed credit constraints and a low interest rate at date 1 , which allow them to transfer the date 2 proceeds of their long investment back into date 1 one for one. On the other side of the trade, patient unprotected agents are not able to earn a return higher than the storage technology between date 1 and date 2 on the proceeds of their date 0 short investment. Thus, in equilibrium, protected agents always end up consuming $\hat{R} e$, and unprotected agents always end up consuming $e$, whatever the realization of their liquidity shocks. This region features an extreme form of redistribution between the two spheres. A large unprotected sphere has the same consumption profile as in the laissez-faire benchmark (i.e., when $\gamma=0$ ) and implicitly subsidizes a small set of protected agents.

Region II When the fraction of protected agents is between two thresholds $\frac{1-\pi}{1-\pi+\hat{R} \pi} \leq \gamma \leq$ $1-\pi$, we say that there is a medium protected sphere. In this case, the mass of unprotected agents is still large enough for protected agents to completely rely on the short asset investment made by unprotected agents. However, the aggregate amount of debt issued by the government is not high enough relative to the supply of funds to push the date 1 interest rate to $\hat{R}$, so impatient protected agents, whose credit constraints are fully relaxed by the bailout, can enjoy 
(a) Investment Choices

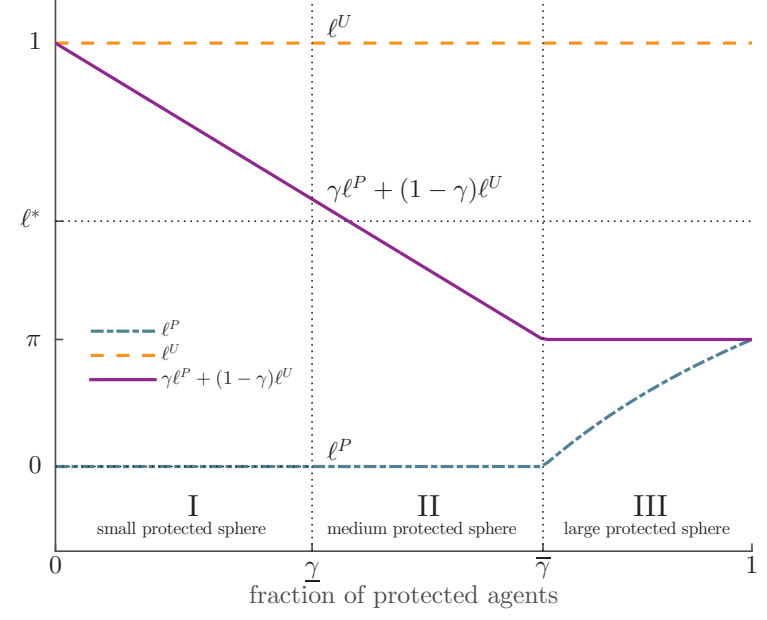

(b) Interest Rate $(1 / q)$

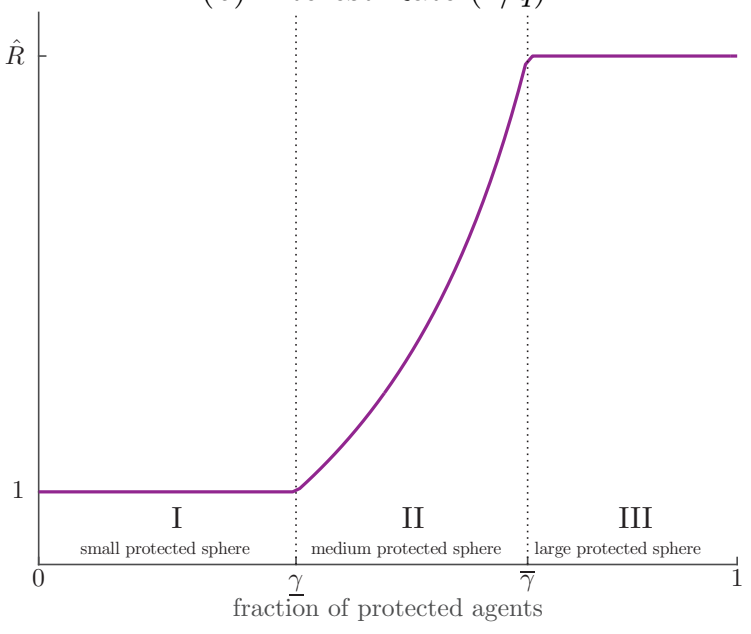

(d) Consumption

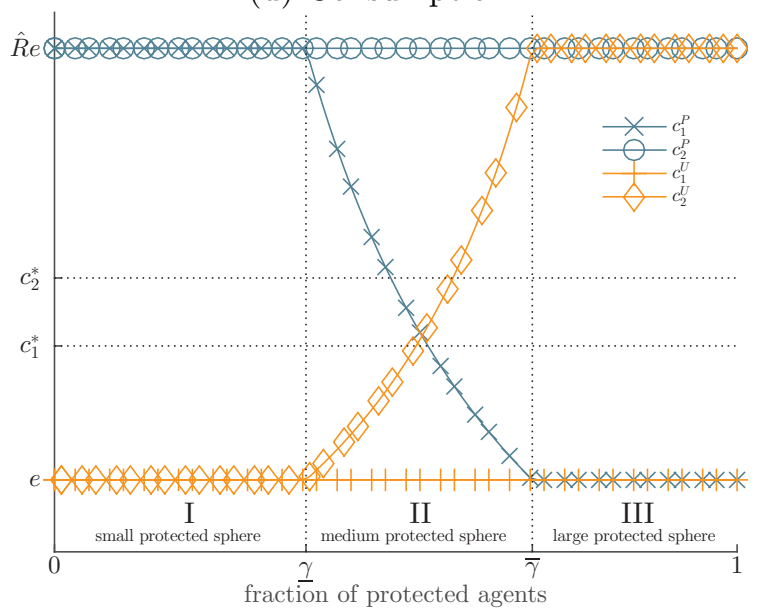

(c) Government Debt $(\mathcal{B})$

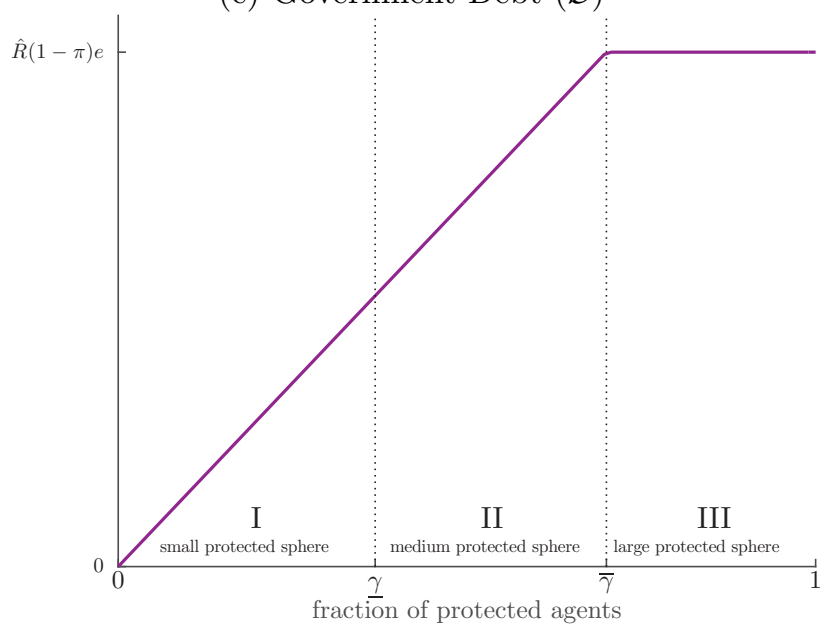

(e) Welfare

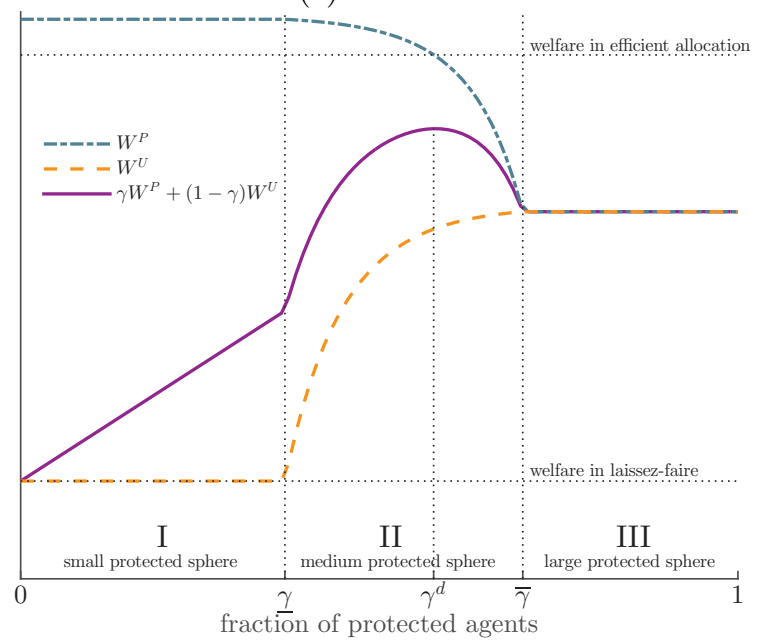

Figure 2: Policies, Welfare, Prices, and the Safety Net 
a consumption level higher than $e$ (the date 0 payoff on their long investment, $\hat{R} e$, is worth more than $e$ when discounted into date 1 at the prevailing interest rate). Patient unprotected agents, on the other hand, earn a positive return, albeit lower than $\hat{R}$, between date 1 and date 2 on the proceeds from their date 0 short investment. Their date 2 consumption is therefore higher than the laissez-faire level of $e$, but it falls short of $\hat{R} e$. This discussion, together with Panel (d) of Figure 2, makes it clear that in this region, government bailouts induce a redistribution of resources from unprotected to protected agents, whose strength decreases with the share of protected agents $\gamma$. As $\gamma$ increases, the gap between the equilibrium consumption of protected and unprotected agents narrows in both liquidity risk contingencies $(\theta=0$ and $\theta=1)$. The fact that this gap is decreasing in $\gamma$ reflects the fact that as $\gamma$ increases, there are fewer and fewer unprotected agents who self-insure by investing in the short asset, which puts an increasing upward pressure on the date 1 interest rate.

Region III When the fraction of protected agents is greater than a threshold $\gamma>1-\pi$, we say that there is a large protected sphere. Protected agents invest only a fraction $L^{P}=\frac{\pi+\gamma-1}{\gamma}$ of their date 0 endowment in the short asset. This fraction is equal to zero when $\gamma=1-\pi$, is increasing in $\gamma$, and reaches $\pi$ when $\gamma=1$. Panel (e) of Figure 2 represents the date 0 investment choice of agents as a function of the size of the protected sphere $\gamma$. Protected agents anticipate being bailed out by the government at date 1 . This a priori eliminates their incentive to self-insure by investing in the short asset. However, someone needs to invest in the short asset to support the consumption of impatient agents at date 1, and when the number of unprotected agents in the economy is small, protected agents need to do their share of short investment at date 0 . Given a full relaxation of credit constraints by the government ex post, for there to be an incentive to invest in the short asset for protected agents, the return on government bonds between date 1 and date 2, $1 / q$, needs to equal the return on the long asset $\hat{R}$. Panel (d) of Figure 2 represents the consumption allocations of agents as a function of the size of the protected sphere $\gamma$. In this region, all impatient agents consume $e$, and all patient agents consume $\hat{R} e$. This consumption allocation strictly dominates the allocation achieved by the benchmark economy without government intervention $(\gamma=0)$. Perhaps surprisingly, protected agents are not better off than unprotected agents in this case, even though the former benefit from a public liquidity provision and the latter do not. Despite not benefiting directly from a public liquidity provision, unprotected agents benefit from it indirectly through the price system. In this region, the government issues aggregate amounts of public debt that are sufficiently high to push the date 1 interest rate on government bonds to its upper bound $\hat{R}$. Unprotected agents who turn out to be patient are thus able to earn a return of $\hat{R}$ between date 
1 and date 2 on the proceeds from their date 0 short investment. This enables them to achieve the same equilibrium consumption profile as protected agents. Panel (b) of Figure 2 displays the interest rate as a function of the size of the protected sphere, and Panel (c) represents aggregate public debt issuance.

To see more clearly why the allocations under commitment are not an equilibrium outcome under discretion, consider the date 0 decision of a protected agent in a fully protected economy, when all other agents hypothetically make the same investment choice as under commitment. Note that this collective investment choice leads to an interest rate such that $1 / q<\hat{R}$ ex post. And given that the government will always relax the protected individual's credit constraint ex post, it is strictly optimal for this agent to invest all if his endowment into the long asset at date 0 . By doing so, he is better off in any contingency. If he turns out patient, he enjoys a strictly higher date 2 consumption of $\hat{R} e>c_{2}^{*}(1)$. If he turns out impatient, he can freely borrow against his date 2 investment income $\hat{R} e$ at an interest rate $1 / q=c_{2}^{*}(1) / c_{1}^{*}(0)$ and hence will also enjoy a strictly higher date 2 consumption of $q \hat{R} e=c_{1}^{*}(0) \hat{R} e / c_{2}^{*}(1)>c_{1}^{*}(0)$. Since there is an incentive for individual deviations, this, of course, cannot constitute an equilibrium. The fundamental problem is that agents free ride on other agents' short investments when the government lacks commitment about its liquidity provision policy, exactly as they would if side trades were available (Jacklin, 1987). ${ }^{17}$

Now that we have fully characterized time-consistent equilibria conditional on the size of the protected sphere $\gamma$, we can finally turn to the analysis of the optimal choice of this parameter by a welfare benevolent government at date 0 .

\subsubsection{Ex ante Policy: Size of the Protected Sphere}

We now consider the date 0 choice of a welfare benevolent government that sets the size of the protected sphere $\gamma$ while anticipating the response of agents in a time-consistent equilibrium. ${ }^{18}$

The government solves

$$
\mathcal{W}_{0}=\max _{\gamma \in[0,1]} \gamma \mathcal{V}_{0}(P, X)+(1-\gamma) \mathcal{V}_{0}(U, X)
$$

subject to

$$
X=(\gamma, \ell(P, X), \ell(U, X))
$$

The following proposition contains our main result.

\footnotetext{
${ }^{17}$ This free rider problem is distinct from the coordination problem typically present in the literature on bailouts (e.g., Farhi and Tirole, 2012, Keister, 2016).

${ }^{18}$ We deliberately abstract from prudential policies that influence agents' portfolio choices at time 0 .
} 
Proposition 4 (Optimal ex ante size of protected sphere). The optimal size of the protected sphere is interior, satisfying $\underline{\gamma}<\gamma^{d}<\bar{\gamma}$.

Proof. See Appendix A.6.

Proposition 4 establishes that the optimal size of the protected sphere is not a corner solution. The optimal safety net architecture from an ex ante perspective features positive masses of protected and unprotected agents. The intuition for this result can most easily be built by considering how welfare depends on $\gamma$ within each of the three regions defined in Section 3.3.2.

Panel (e) of Figure 2 represents ex ante average welfare as a function of the size of the protected sphere $\gamma$. We first note that ex ante average welfare is continuous in $\gamma$ since all equilibrium consumption allocations are continuous in $\gamma$. In region I, protected agents always consume $\hat{R} e$, whereas unprotected agents always consume $e$. Hence in that region, the welfare of protected agents is strictly higher than that of unprotected agents. It follows that ex ante average welfare is strictly increasing in $\gamma$ in that region, with a maximum of $\underline{\gamma} u(e)+(1-\underline{\gamma}) u(\hat{R} e)$ at the upper bound $\gamma=\underline{\gamma}$. Safety net architectures with small protected sectors strictly dominate the laissez-faire benchmark $(\gamma=0)$ because protected agents are strictly better off than in the laissez-faire benchmark and unprotected agents are no worse off. In region III, protected and unprotected agents consume the same amounts in equilibrium in the contingency in which they are patient. Likewise, they consume the same in the contingency in which they are impatient. It follows that within this region, ex ante average welfare is constant with respect to $\gamma$ and given by $\pi u(e)+(1-\pi) \rho u(\hat{R} e)$. We also note that since $\underline{\gamma}<1-\pi$, ex ante average welfare is strictly higher in region III than in region I. By the continuity of ex ante average welfare with respect to $\gamma$, it must therefore be that the optimal size of the protected sphere falls in region II. But a key feature of our first result in Proposition 4 is that the optimal size of the protected sphere lies in the interior of region II rather than at its right boundary, so that the optimal safety net architecture strictly dominates a fully protected economy.

The ex ante optimality of restricting the scope of protection in the economy can be drawn from the fact that the left derivative of ex ante average welfare is strictly negative at $\gamma=\bar{\gamma}=$ $1-\pi$. The intuition has to do with the improvement in risk sharing induced by the splitting of agents between a protected and an unprotected sphere. In region II, a marginal decrease in $\gamma$ causes a decrease in the equilibrium date 1 interest rate. Since in this region impatient protected agents borrow in equilibrium from patient unprotected agents, this decrease in the interest rate redistributes wealth from the latter to the former. ${ }^{19}$ At $\gamma=\bar{\gamma}=1-\pi$, such a wealth redistribution is necessarily socially desirable given that (i) the masses of patient

\footnotetext{
${ }^{19}$ The effect of this redistribution on equilibrium consumption can be inferred from Panel (d) of Figure 2.
} 
unprotected and impatient protected agents are equal (i.e., to $\pi(1-\pi)$ ), and (ii) relative to the efficient allocation, impatient agents consume too little and patient agents consume too much (a consequence of Assumption 1). Hence, a marginal decrease in the share of protected agents from $\gamma=1-\pi$ unambiguously increases the ex ante average welfare criterion. It directly follows that the optimal size of the protected sphere $\gamma^{d}$ must lie strictly between $\underline{\gamma}$ and $\bar{\gamma}$. This intuition is illustrated in Panel (e) of Figure 2. There, it is apparent that directly to the left of $\gamma=\bar{\gamma}=1-\pi$, the welfare increase for protected agents more than offsets the welfare decrease for unprotected agents, so that ex ante average welfare is strictly decreasing in $\gamma$.

The optimal size of the safety net $\gamma^{d}$ then balances the risk-sharing benefits just described with the costs induced by a distortion resulting from a dispersion in the consumption of protected and unprotected agents. In region III, this distortion is absent, since all impatient agents consume $e$ and all patient agents consume $\hat{R} e$. But in region II, when $\gamma$ is lowered starting from $\bar{\gamma}$, consumption gaps of $c_{1}^{P}(0)-c_{1}^{U}(0)=(1-\pi-\gamma) e /(\pi \gamma)$ and $c_{2}^{P}(1)-c_{2}^{U}(1)=(1-\pi-\gamma) \hat{R} e /[(1-\pi)(1-\gamma)]$ emerge between protected and unprotected agents. These gaps are decreasing in $\gamma$. Therefore, the optimal safety net $\gamma^{d}$ can be seen as the point where, from the perspective of the government, the benefits arising from the (pecuniary externality induced) redistribution between unprotected patient agents and protected impatient agents just offset the costs arising from the distortion between protected and unprotected agents.

How does the safety net vary with fundamental parameters of the economy? The following proposition characterizes how the size of the safety net varies with the probability of experiencing a liquidity shock and the return on the long asset.

Proposition 5 (Comparative statics). The optimal size of the protected sphere $\gamma$ is strictly decreasing in the probability of experiencing a liquidity shock (i.e., $\left.\partial \gamma^{d} / \partial \pi<0\right)$ and weakly decreasing in the long asset return (i.e., $\left.\partial \gamma^{d} / \partial \hat{R} \leq 0\right)$.

Proof. See Appendix A.7.

The interpretation of these comparative statics results can be framed in terms of the trade-off described above. We start by discussing the partial effect of $\pi$. Consider a marginal increase in $\pi$ from $\pi_{0}$ to $\pi_{1}$, and label the optimal safety nets associated with $\pi_{0}$ and $\pi_{1}$ by $\gamma_{0}^{d}$ and $\gamma_{1}^{d}$, respectively. At $\gamma_{0}^{d}$, the risk-sharing benefits of lowering $\gamma$ further are larger for $\pi_{1}$ than for $\pi_{0}$, both because the interest rate becomes more sensitive to $\gamma$ as $\pi$ grows (i.e., $\partial(1 / q) /(\partial \gamma \partial \pi)>0)$ and because the gap in consumption between patient unprotected and impatient protected agents increases with a higher $\pi$ (i.e., $c_{2}^{U}(1)-c_{1}^{P}(0)$ is increasing in $\pi$ ). Meanwhile, the distortionary costs of lowering $\gamma$ further diminish, as the consumption gaps between protected and unprotected agents get smaller as $\pi$ grows (i.e., $c_{1}^{P}(0)-c_{1}^{U}(0)$ and $c_{2}^{P}(1)-c_{2}^{U}(1)$ are both decreasing 
in $\pi$ ). In a nutshell, as the probability of liquidity shocks increases, manipulating the size of the safety net to improve social insurance becomes simultaneously more powerful, more beneficial, and less costly. As a result, $\gamma_{1}^{d}$ must be strictly lower than $\gamma_{0}^{d}$.

The interpretation of the partial effect of $\hat{R}$ is more subtle because it involves counteracting effects. Consider a marginal increase in $\hat{R}$ from $\hat{R}_{0}$ to $\hat{R}_{1}$, and label the optimal safety nets associated with $\hat{R}_{0}$ and $\hat{R}_{1}$ by $\gamma_{0}^{d}$ and $\gamma_{1}^{d}$, respectively. At $\gamma_{0}^{d}$, the risk-sharing benefits of lowering $\gamma$ further are larger for $\hat{R}_{1}$ than for $\hat{R}_{0}$, both because the interest rate becomes more sensitive to $\gamma$ as $\hat{R}$ grows (i.e., $\partial(1 / q) /(\partial \gamma \partial \hat{R})>0)$ and because the gap in consumption between patient unprotected and impatient protected agents increases with a higher $\hat{R}$ (i.e., $c_{2}^{U}(1)-c_{1}^{P}(0)$ is increasing in $\hat{R}$ ). However, this time the distortionary costs of lowering $\gamma$ further increase with $\hat{R}$ as well, as the consumption gap between protected and unprotected agents who are patient gets larger as $\hat{R}$ grows (i.e., $c_{1}^{P}(0)-c_{1}^{U}(0)$ does not vary with $\hat{R}$ but $c_{2}^{P}(1)-c_{2}^{U}(1)$ is increasing in $\hat{R}$ ). In a nutshell, as the return on the long asset increases, manipulating the size of the safety net to improve social insurance becomes more powerful and more beneficial, but also more costly. When risk aversion is exactly one, these two effects happen to cancel out, whereas when it is larger than one, the first effect dominates. As a result, we have $\gamma_{1}^{d} \leq \gamma_{0}^{d}$, with $=$ only if $-c u^{\prime \prime}(c) / u^{\prime}(c)=1 \forall c>0$.

\subsubsection{Extension and Robustness}

In this section, we consider the relaxation of two previously maintained assumption and explain why our main result is robust to these changes.

Absence of commitment over $\gamma$. We have assumed throughout that the government could commit not to bail out a measure $1-\gamma$ of agents. Here, we show that even if the government has the possibility of changing the value of $\gamma$ ex post, it has no incentive to deviate from $\gamma^{d}$ when the market anticipated that the government would implement $\gamma^{d}$. To be clear, we maintain the assumption that if an unprotected agent individually deviates at time 0 by investing in long assets, he would not receive a bailout from the government. ${ }^{20}$

It is straightforward to show that the value $\gamma^{d}$ derived in Section 3.3.3 under the assumption that the government could commit to its choice of $\gamma$ remains implementable when the government can renege on its announcement. For a given value of $\gamma$ anticipated by agents at date 0 ,

\footnotetext{
${ }^{20}$ That is, the government is able to commit to not bail out an agent who, following the government's ex post choice of $\gamma$, ends up belonging to the unprotected sphere.
} 
the government's date 1 problem is now

$$
\begin{aligned}
\max _{\tilde{\gamma},\left\{s_{j}\right\}_{j \in[0,1]},\left\{B_{j}\right\}_{j \in[0, \tilde{\gamma}]}} & \int_{0}^{1} \gamma\left[\pi \mathcal{V}_{1}\left(s_{i}, L^{P}, 0, X\right)+(1-\pi) \mathcal{V}_{1}\left(s_{i}, L^{P}, 1, X\right)\right] \\
& +(1-\gamma)\left[\pi \mathcal{V}_{1}\left(s_{i}, L^{U}, 0, X\right)+(1-\pi) \mathcal{V}_{1}\left(s_{i}, L^{U}, 1, X\right)\right] d i
\end{aligned}
$$

subject to $\int_{0}^{1} \mathbb{I}_{\left\{s_{i}=P\right\}} d i=\tilde{\gamma}$, for $X=\left(\gamma, L^{P}, L^{U}\right)$.

To see that the value of $\gamma$ chosen in problem (27) remains optimal ex post, we observe that substituting $X=\left(\gamma^{d}, 0,1\right)$ into $(28)$ gives a government's ex post payoff of ${ }^{21}$

$$
\tilde{\mathcal{W}}= \begin{cases}\mathcal{W}_{0}-\left(\gamma^{d}-\tilde{\gamma}\right) \pi \underbrace{[u(q(X) \hat{R} e)-u(0)]}_{>0} & \text { for } \tilde{\gamma}<\gamma^{d} \\ \mathcal{W}_{0} & \text { for } \tilde{\gamma} \geq \gamma^{d},\end{cases}
$$

where $\mathcal{W}_{0}$ is the government's payoff under commitment over $\gamma$ in (27). Hence, reneging upon its date 0 announcement to choose a lower $\gamma$ is not optimal for the government. The reason is that in doing so, the government would leave some impatient agents who anticipated to be protected, and hence invested all of their endowment in the long asset, with zero consumption. Similarly, the government cannot increase its payoff by choosing a higher $\gamma$ ex post. This time the reason is that reneging on the announcement would extend the safety net to impatient agents who do not need it anyway because they anticipated being unprotected and hence invested all of their endowment in the short asset.

Private market. We have assumed throughout that enforcement problems are such that private borrowing is fully precluded. Under a milder assumption on enforcement, we could have instead assumed that private credit is possible but constrained. In that case, (13) would be replaced by

$$
\kappa(s, \ell, X) \equiv \begin{cases}\bar{d} & \text { for } s=U \\ q(X)[B(\ell)+\bar{d}] & \text { for } s=P\end{cases}
$$

for $\bar{d}>0$. For a sufficiently tight private borrowing constraint $\bar{d}{ }^{22}$ all of our qualitative results would apply. In particular, despite impatient unprotected agents being hurt by higher interest rate, it would still be ex post optimal for the government to fully relax impatient protected agents' credit constraint so that the bailout policy of Proposition 2 would become

\footnotetext{
${ }^{21}$ It is straightforward to see that it is optimal to choose $\left\{s_{j}\right\}_{j \in[0,1]}$ such that $\mathbb{I}_{\left\{s_{i}=P\right\}}$ is weakly decreasing in $i$, for it would not be optimal to "unprotect" more than the minimum measure of agents who expected to be protected.

${ }^{22}$ More precisely, for $\bar{d} \leq e(1-\pi)\left\{u^{\prime}(e) /\left[\rho u^{\prime}(\hat{R} e)\right]-1\right\}^{-1}$.
} 
$B^{d}(\ell)=\hat{R}(1-\ell) e-\bar{d}$. Given the possibility of limited private credit, unprotected agents' equilibrium investment in the short asset would be lowered to $L^{U}=1-\bar{d} /(\hat{R} e)$, as would the thresholds of Proposition 3, which would generalize to $\underline{\gamma}(\bar{d}) \equiv[1-\bar{d} /(\hat{R} e)]^{-1}[\underline{\gamma}-\bar{d} /(\hat{R} e)]$ and $\bar{\gamma}(\bar{d}) \equiv[1-\bar{d} /(\hat{R} e)]^{-1}[\bar{\gamma}-\bar{d} /(\hat{R} e)] .{ }^{23}$ Our main result on the optimality of an interior safety net would hence be preserved.

\section{Conclusion}

In this paper, we presented a model of financial safety net. We study a workhorse model of liquidity demand with limited private credit, in which the government chooses the share of investors that will be eligible for liquidity support.Our analysis delivers the following key results. First, if the government can commit about future policies, the optimal financial safety net covers all agents. Second, when the government lacks commitment, the government provides excessive liquidity to agents protected by the safety net. Third, in the absence of commitment, the optimal financial safety net includes only a subset of agents. Compared with an economy where all agents are protected, this results in more liquid asset portfolios, lower interest rates, and superior social insurance.

Our analysis underscores the importance of the institutional design of central banks' framework for liquidity provision. Following the financial crisis, there have been calls to expand the safety net to include shadow banks. Our paper presents a cautionary note to this view and highlights that expanding the safety net could lead to underinvestment in liquid assets and too little risk sharing. We do abstract, however, from important elements, such as liquidity regulation and issues of regulatory arbitrage. In Grochulski and Zhang (2015), for example, liquidity regulation improves risk sharing, but investors can bypass regulation at a cost, by engaging in shadow banking activities. An interesting approach would be to investigate the interaction between liquidity regulation, regulatory arbitrage, and financial safety nets, and how this interaction affects risk sharing and moral hazard.

\footnotetext{
${ }^{23}$ Details are available from the authors upon request.
} 


\section{References}

Acharya, Viral V and Tanju Yorulmazer, "Too Many to Fail-An Analysis of TimeInconsistency in Bank Closure Policies," Journal of Financial Intermediation, 2007, 16 (1), $1-31$.

Acharya, Viral V., Philipp Schnabl, and Gustavo Suarez, "Securitization without Risk Transfer," Journal of Financial Economics, 2013, 107 (3), 515-536.

Akerlof, George A, "The Market for "lemons": Quality Uncertainty and the Market Mechanism," The quarterly journal of economics, 1970, pp. 488-500.

Bhandari, Anmol, David Evans, Mikhail Golosov, and Thomas J Sargent, "Taxes, Debts, and Redistributions with Aggregate Shocks," 2015. NBER Working Paper No. 19470.

Bianchi, Javier, "Efficient Bailouts?," American Economic Review, 2016, 106 (12), 36073659 .

Chari, V.V. and P.J. Kehoe, "Bailouts, Time Inconsistency and Optimal Regulation," Forthcoming, American Economic Review, 20016.

Diamond, Douglas W. and Philip H. Dybvig, "Bank Runs, Deposit Insurance, and Liquidity," Journal of Political Economy, 1983, 91 (3), 401-419.

Diamond, Douglas W and Raghuram G Rajan, "Illiquid Banks, Financial Stability, and Interest Rate Policy," Journal of Political Economy, 2012, 120 (3), 552-591.

Farhi, Emmanuel and Jean Tirole, "Collective Moral Hazard, Maturity Mismatch, and Systemic Bailouts," American Economic Review, 2012, 102 (1), 60-93.

_, Mikhail Golosov, and Aleh Tsyvinski, "A Theory of Liquidity and Regulation of Financial Intermediation," Review of Economic Studies, 2009, 76 (3), 973-992.

Freixas, Xavier, "Optimal bail out policy, conditionality and constructive ambiguity," 1999. Financial Market Group Discussion Paper 237, LSE.

Gorton, Gary and Andrew Metrick, "Securitized Banking and the Run on Repo," Journal of Financial Economics, 2012, 104 (3), 425-451.

Greenspan, Alan, "Speech at the 37th Annual Conference on Bank Structure and Competition of the Federal Reserve Bank of Chicago, Chicago, Illinois," 2001. 
Grochulski, Borys and Yuzhe Zhang, "Optimal Liquidity Regulation with Shadow Banking," 2015. Working paper WP 15-12R, Federal Reserve Bank Richmond.

Holmström, Bengt and Jean Tirole, "Private and Public Supply of Liquidity," Journal of Political Economy, 1998, 106 (1), 1-40.

Jacklin, Charles J., "Demand Deposits, Trading Restrictions, and Risk Sharing," 1987.

Keister, Todd, "Bailouts and Financial Fragility," Review of Economic Studies, 2016, 83 (2), 704-736.

- and Vijay Narasiman, "Expectations vs. Fundamentals-Driven Bank Runs: When Should Bailouts be Permitted?," Review of Economic Dynamics, 2016, 21, 89-104.

Kiyotaki, Nobuhiro and John Moore, "Liquidity, business cycles, and monetary policy," 2012. NBER Working Paper No. 17934.

Nosal, Jaromir and Guillermo Ordoñez, "Uncertainty as commitment," Journal of Monetary Economics, 2016, 80, 124-140.

Ordoñez, Guillermo, "Sustainable Shadow Banking," 2013. NBER Working Paper No. 19022.

Plantin, Guillaume, "Shadow Banking and Bank Capital Regulation," Review of Financial Studies, 2015, 28 (1), 146-175.

Pozsar, Zoltan, Tobias Adrian, Adam Ashcraft, and Hayley Boesky, "Shadow banking," 2010. Staff Report 458, Federal Reserve Bank of New York.

Woodford, Michael, "Public Debt as Private Liquidity," The American Economic Review, 1990, $80(2), 382-388$.

Yared, Pierre, "Public Debt under Limited Private Credit," Journal of the European Economic Association, 2013, 1 (2), 229-245.

_ , "Optimal Fiscal Policy in an Economy with Private Borrowing Limits," 2015. Mimeo, Columbia. 


\section{Appendix}

\section{A Proofs}

\section{A.1 Proof of Lemma 1}

Step 1 : Date 1 consumption choice

A type $s$ agent solves the following date 1 problem:

$$
\begin{aligned}
\mathcal{V}_{1}(s, \ell, \theta, X)=\max _{c_{1}, c_{2}} U\left(c_{1}, c_{2}, \theta\right) \\
\text { subject to } \\
c_{1}+q(X) c_{2}=\ell e+q(X) \hat{R}(1-\ell) e \\
c_{1} \leq \ell e+\kappa(s, \ell, X) \\
c_{1}, c_{2} \geq 0 .
\end{aligned}
$$

Note that $c_{2}$ cannot be negative. Thus, for an agent who turns out to be impatient (type $\theta=0$ ) at date 1 , it is optimal to maximize $c_{1}$ and minimize $c_{2}$. It must therefore be that

$$
\mathcal{C}_{1}(s, \ell, 0, X)=\ell e+\min \{q(X) \hat{R}(1-\ell) e, \kappa(s, \ell, X)\}
$$

and

$$
\mathcal{C}_{2}(s, \ell, 0, X)=\max \left\{\hat{R}(1-\ell) e-\frac{\kappa(s, \ell, X)}{q(X)}, 0\right\}
$$

For an agent who turns out to be patient (type $\theta=1$ ) at date 1 , it is weakly (strongly if $q<1$ ) optimal to set $c_{1}=0$ and ${ }^{24}$

$$
\mathcal{C}_{2}(s, \ell, 1, X)=\hat{R}(1-\ell) e+\frac{\ell e}{q(X)}
$$

Step 2: Bonds price

First, note that the opportunity to invest in the short asset at date 1 requires that $q \leq 1$. We now show that conditional on the aggregate state $X$, if $q(X)<1$, then it must satisfy

$$
q(X)=\frac{\mathcal{C}_{1}\left(s, L^{s}, 0, X\right)}{\mathcal{C}_{2}\left(s, L^{s}, 1, X\right)-\mathcal{C}_{2}\left(s, L^{s}, 0, X\right)}=e \frac{1-\pi}{\pi} \frac{\gamma L^{P}+(1-\gamma) L^{U}}{\gamma \min \left\{\hat{R}\left(1-L^{P}\right) e, B\left(L^{P}\right)\right\}}
$$

To establish this, we use the fact that in equilibrium, we must have $\ell=L^{s}$ for the agents of

\footnotetext{
${ }^{24}$ When $q \geq 1$, any plan such that $c_{1}+c_{2}=\hat{R}(1-\ell) e+\ell e$ (and $c_{1}, c_{2} \geq 0$ ) is also optimal for a patient agent, but we can focus without loss of generality on the one featuring $c_{1}=0$ and $c_{2}=\hat{R}(1-\ell) e+\ell$.
} 
type $s$ (consistency). From (A.2) and $\mathcal{C}_{1}\left(s, L^{s}, 1, X\right)=0$, we have

$$
\begin{aligned}
\mathcal{C}_{1}\left(s, L^{s}, 0, X\right)+q(X) \mathcal{C}_{2}\left(s, L^{s}, 0, X\right) & =L^{s} e+q \hat{R}\left(1-L^{s}\right) \\
q(X) \mathcal{C}_{2}\left(s, L^{s}, 1, X\right) & =L^{s} e+q \hat{R}\left(1-L^{s}\right) .
\end{aligned}
$$

Combining these two equations allows us to obtain the first equality in (A.7):

$$
q(X)=\frac{\mathcal{C}_{1}\left(s, L^{s}, 0, X\right)}{\mathcal{C}_{2}\left(s, L^{s}, 1, X\right)-\mathcal{C}_{2}\left(s, L^{s}, 0, X\right)} \quad \text { for } s \in\{U, P\}
$$

which itself implies

$$
q(X)=\frac{\gamma \mathcal{C}_{1}\left(P, L^{P}, 0, X\right)+(1-\gamma) \mathcal{C}_{1}\left(U, L^{U}, 0, X\right)}{\gamma\left[\mathcal{C}_{2}\left(P, L^{P}, 1, X\right)-\mathcal{C}_{2}\left(P, L^{P}, 0, X\right)\right]+(1-\gamma)\left[\mathcal{C}_{2}\left(U, L^{U}, 1, X\right)-\left(\mathcal{C}_{2}\left(U, L^{U}, 0, X\right)\right]\right.}
$$

Now, as $q<1$, agents do not invest in short assets between date 1 and date 2 , since they could otherwise make themselves strictly better off by saving in public bonds. Thus, the market clearing condition for date 1 consumption holds with equality:

$$
\sum_{s} \sum_{\theta} \gamma_{s} \pi_{\theta} \mathcal{C}_{1}\left(s, L^{s}, \theta, X\right)=\sum_{s} \gamma_{s} L^{s} e
$$

Along with the fact that $\mathcal{C}_{1}\left(s, L^{s}, 1, X\right)=0$ for $s \in\{P, U\}$, this implies

$$
\gamma \mathcal{C}_{1}\left(P, L^{P}, 0, X\right)+(1-\gamma) \mathcal{C}_{1}\left(U, L^{U}, 0, X\right)=\frac{e}{\pi}\left(\gamma L^{P}+(1-\gamma) L^{U}\right)
$$

Using (A.5) (with (13)) and (A.6), the denominator in (A.9) is given by

$$
\begin{array}{r}
\gamma\left[\mathcal{C}_{2}\left(P, L^{P}, 1, X\right)-\mathcal{C}_{2}\left(P, L^{P}, 0, X\right)\right]+(1-\gamma)\left[\mathcal{C}_{2}\left(U, L^{U}, 1, X\right)-\mathcal{C}_{2}\left(U, L^{U}, 0, X\right)\right] \\
=\frac{\gamma L^{P}+(1-\gamma) L^{U}}{q(X)} e+\gamma \min \left\{\hat{R}\left(1-L^{P}\right) e, B\left(L^{P}\right)\right\}
\end{array}
$$

Substituting (A.10) and (A.11) into (A.9) yields, after some algebraic manipulation, to the second equality in (A.7):

$$
q(X)=e \frac{1-\pi}{\pi} \frac{\gamma L^{P}+(1-\gamma) L^{U}}{\gamma \min \left\{\hat{R}\left(1-L^{P}\right) e, B\left(L^{P}\right)\right\}} .
$$

Since the opportunity to invest in the short asset at date 1 requires that $q \leq 1$, the general 
bond price expression in a continuation equilibrium is given by

$$
q(X)=\min \left\{e \frac{1-\pi}{\pi} \frac{\gamma L^{P}+(1-\gamma) L^{U}}{\gamma \min \left\{\hat{R}\left(1-L^{P}\right) e, B\left(L^{P}\right)\right\}}, 1\right\}
$$

\section{A.2 Proof of Lemma 2}

We start by establishing that $c_{2}^{*}(0)=c_{1}^{*}(1)=0$. First, $c_{2}(0)>0$ cannot be optimal, since impatient agents do not value consumption at date 2 . Second, if it were the case that $c_{1}(1)>0$, then the planner could decrease $c_{1}(1)$ by some $\epsilon>0$ arbitrarily small while increasing $c_{2}(1)$ by $\epsilon \hat{R}$ and while still satisfying the resource constraint (11) and strictly increasing welfare.

Next, we characterize $c_{1}^{*}(0)$ and $c_{2}^{*}(1)$. The planner's first-order condition with respect to $c_{1}(0)$ and $c_{2}(1)$ is given by

$$
u^{\prime}\left(c_{1}^{*}(0)\right)=\rho \hat{R} u^{\prime}\left(c_{2}^{*}(1)\right) .
$$

Since $\rho \hat{R}>1$ by Assumption 1, this implies that $c_{1}^{*}(0)<c_{2}^{*}(1)$. As shown in Diamond and Dybvig (1983) (footnote 3), condition (2) on the relative risk aversion in Assumption 1 further implies that $u^{\prime}(e)>\rho \hat{R} u^{\prime}(\hat{R} e)$, and therefore that $c_{1}^{*}(0)>e$ and $c_{2}^{*}(1)<\hat{R} e$.

\section{A.3 Proof of Proposition 1}

We show that $\gamma=1$ and $B=(1-\pi) c_{2}^{*}(1)$ achieve the efficient allocation described in Lemma 2 . Since this safety net architecture only features protected agents, we ignore unprotected agents in what follows.

The protected agents' date 0 problem is

$$
\max _{\ell \in[0,1]} \pi u(\ell e+q \min \{\hat{R}(1-\ell) e, B\})+(1-\pi) \rho u\left(\hat{R}(1-\ell) e+\frac{\ell e}{q}\right)
$$

We consider separately the agent's problem in the two intervals $[0,1-B /(\hat{R} e)]$ and $[1-$ $B /(\hat{R} e), 1]$. In the first interval, the problem is

$$
\max _{\ell \in\left[0,1-\frac{B}{\hat{R} e}\right]} \pi u(\ell e+q B)+(1-\pi) \rho u\left(\hat{R}(1-\ell) e+\frac{\ell e}{q}\right)
$$

The first-order condition is given by

$$
\Psi(\ell) \equiv e \pi u^{\prime}(\ell e+q B)-e(1-\pi) \rho\left(\hat{R}-\frac{1}{q}\right) u^{\prime}\left(\hat{R}(1-\ell) e+\frac{\ell e}{q}\right) \lesseqgtr 0
$$

with " $\leq$ " if $\ell=0, " \geq 0$ " if $\ell=1-B /(\hat{R} e)$, and "=" if $\ell \in(0,1-B /(\hat{R} e))$. Note that the 
agent's objective function is strictly concave in $\ell$, as $\Psi^{\prime}(\cdot)<0$ for $\ell \in[0,1-B /(\hat{R} e)]$. In the second interval, the problem is

$$
\max _{\ell \in\left[1-\frac{B}{R}, 1\right]} \pi u(\ell e+q \hat{R}(1-\ell) e)+(1-\pi) \rho u\left(\hat{R}(1-\ell) e+\frac{\ell e}{q}\right) .
$$

We conjecture that the policy consisting of $\gamma=1$ and $B=(1-\pi) c_{2}^{*}(1)$ leads to an equilibrium collective choice of $L^{P}=1-B /(\hat{R} e)=1-(1-\pi) c_{2}^{*}(1) /(\hat{R} e)=\pi c_{1}^{*}(0) / e$, and verify this conjecture. Under the conjecture, the bond price is given by

$$
q=\min \left\{e \frac{1-\pi}{\pi} \frac{L^{P}}{\hat{R}\left(1-L^{P}\right) e}, 1\right\}=\frac{1-\pi}{\pi} \frac{L^{P}}{\hat{R}\left(1-L^{P}\right)}=\frac{c_{1}^{*}(0)}{c_{2}^{*}(1)}<1 .
$$

Starting with the first interval, we have

$$
\begin{aligned}
\Psi\left(1-\frac{B}{\hat{R} e}\right) & \equiv e \pi u^{\prime}\left(c_{1}^{*}(0)\right)-(1-\pi) e\left(\hat{R}-\frac{1}{q}\right) \rho u^{\prime}\left(c_{2}^{*}(1)\right) \\
& >e \pi u^{\prime}\left(c_{1}^{*}(0)\right)-(1-\pi) e(\hat{R}-1) \rho u^{\prime}\left(c_{2}^{*}(1)\right) \\
& >e[\pi-\rho(1-\pi) e(\hat{R}-1)] u^{\prime}\left(c_{1}^{*}(0)\right)>0,
\end{aligned}
$$

where the last inequality follows from Assumption 2. The fact that $\Psi(1-B /(\hat{R} e))>0$ implies that within this first interval, $\ell=1-B /(\hat{R} e)$ is optimal. Since the conjecture induces a bond price such that $q=c_{1}^{*}(0) / c_{2}^{*}(1)>1 / \hat{R}$, in the second interval the agent's objective function is strictly decreasing in $\ell$, so $\ell=1-B /(\hat{R} e)$ is optimal. We have thus verified that the privately optimal investment choice over $\ell \in[0,1]$ is consistent with the conjectured aggregate investment choice above. The fact that the policy in question achieves the efficient allocation follows from simple algebra.

\section{A.4 Proof of Proposition 2}

At date 1 , the government chooses a debt issuance policy $B(\ell)$ to maximize the average welfare of agents, subject to the private sector's date 1 response to its action. The government solves

$$
\max _{\left\{B_{j}\right\}_{j \in[0, \gamma]}} \int_{0}^{\gamma}\left[\pi \mathcal{V}_{1}\left(P, \ell_{j}, 0, X\right)+(1-\pi) \mathcal{V}_{1}\left(P, \ell_{j}, 1, X\right)\right] d i+\int_{\gamma}^{1}\left[\pi \mathcal{V}_{1}\left(U, \ell_{j}, 0, X\right)+(1-\pi) \mathcal{V}_{1}\left(U, \ell_{j}, 1, X\right)\right] d j
$$


Using Lemma 1, this problem can be written as

$$
\begin{aligned}
\max _{\left\{B_{j}\right\}_{j \in[0, \gamma]}} & \int_{0}^{\gamma}\left[\pi u\left(\ell_{j} e+q(X) \min \left\{\hat{R}\left(1-\ell_{j}\right) e, B_{j}\right\}\right)+(1-\pi) \rho u\left(\hat{R}\left(1-\ell_{j}\right) e+\frac{\ell_{j} e}{q}\right)\right] d j \\
& +\int_{\gamma}^{1}\left[\pi u\left(\ell_{j} e\right)+(1-\pi) \rho u\left(\hat{R}\left(1-\ell_{j}\right) e+\frac{\ell_{j} e}{q}\right)\right] d j
\end{aligned}
$$

subject to ${ }^{25}$

$$
q=\min \left\{e \frac{1-\pi}{\pi} \frac{\int_{0}^{1} \ell_{j} d j}{\int_{0}^{\gamma} \min \left\{\hat{R}\left(1-\ell_{j}\right) e, B_{j}\right\} d j}, 1\right\} .
$$

The first-order condition for $B_{i}$ is

$$
\begin{gathered}
\mathbb{I}_{\left\{B_{i}<\hat{R}\left(1-\ell_{i}\right) e\right\}} \pi u^{\prime}\left(\ell_{i} e+q B_{i}\right) q+ \\
\mathbb{I}_{\left\{e \frac{1-\pi}{\pi} \frac{\int_{0}^{1} \ell_{j} d j}{\int_{0}^{\gamma} \min \left\{\hat{R}\left(1-\ell_{j}\right) e, B_{j}\right\} d j}<1\right\}} \times \mathbb{I}_{\left\{B_{i}<\hat{R}\left(1-\ell_{i}\right) e\right\}}\left[-\frac{q}{\int_{0}^{\gamma} \min \left\{\hat{R}\left(1-\ell_{j}\right) e, B_{j}\right\} d j}\right] \\
\times\left[\pi \int_{0}^{\gamma} u^{\prime}\left(\ell_{j} e+q \min \left\{\hat{R}\left(1-\ell_{j}\right) e, B_{j}\right\}\right) \min \left\{\hat{R}\left(1-\ell_{j}\right) e, B_{j}\right\} d j\right. \\
\left.+(1-\pi) \rho \int_{0}^{1} u^{\prime}\left(\hat{R}\left(1-\ell_{j}\right) e+\frac{\ell_{j} e}{q}\right)\left(-\frac{\ell_{j} e}{q^{2}}\right) d j\right]=0 .
\end{gathered}
$$

To show that the optimal bailout rule satisfies $B(\ell) \geq \hat{R}(1-\ell) e$, suppose otherwise, seeking a contradiction. Then the first-order condition, evaluated at symmetric date 0 investment choices, becomes

$$
+\mathbb{I}_{\left\{e \frac{1-\pi}{\pi} \frac{\int_{0}^{1} \ell_{j} d j}{\gamma B_{i}}<1\right\}}\left[-\frac{q}{\gamma B_{i}}\right] \times\left[\pi \gamma u^{\prime}\left(\ell_{i} e+q B_{i}\right) B_{i}+(1-\pi) \rho u^{\prime}\left(\hat{R}\left(1-\ell_{i}\right) e+\frac{\ell_{i} e}{q}\right)\left(-\frac{\ell_{i} e}{q^{2}}\right)\right]=0 .
$$

If $e \frac{1-\pi}{\pi} \frac{\int_{0}^{1} \ell_{j} d j}{\gamma B_{i}} \geq 1$, we are left with $\pi u^{\prime}\left(\ell_{i} e+q B_{i}\right) q=0$, which is a contradiction. If $e \frac{1-\pi}{\pi} \frac{\int_{0}^{1} \ell_{j} d j}{\gamma B_{i}}<$ 1 , we have

$$
(1-\pi) \rho u^{\prime}\left(\hat{R}\left(1-\ell_{i}\right) e+\frac{\ell_{i} e}{q}\right) \frac{\ell_{i} e}{q \gamma B_{i}}=0,
$$

which is also a contradiction. It follows that the optimal rule satisfies $B(\ell) \geq \hat{R}(1-\ell) e$. Note that any such rule trivially satisfies the first-order condition, since in that case the indicator variable $\mathbb{I}_{\left\{B_{i}<\hat{R}\left(1-\ell_{i}\right) e\right\}}$ is zero. Without loss of generality, the solution is thus $B(\ell)=\hat{R}(1-\ell) e$.

\footnotetext{
${ }^{25}$ This equilibrium price expression is obtained by a procedure analogous to that of Lemma 1 , but without (yet) imposing the symmetry of date 0 investment choices.
} 


\section{A.5 Proof of Proposition 3}

Step 1 : Date 0 short asset choice

An agent at date 0 faces this problem:

$$
\mathcal{V}_{0}(s, X)=\max _{\ell \in[0,1]} \pi u\left(\mathcal{C}_{1}(s, \ell, 0, X)\right)+(1-\pi) \rho u\left(\mathcal{C}_{1}(s, \ell, 1, X)+\mathcal{C}_{2}(s, \ell, 1, X)\right)
$$

subject to (A.4) with $B(\ell)=\hat{R}(1-\ell) e,(\mathrm{~A} .6)$, and $(24)$.

First, it is useful to prove that $1 / \hat{R} \leq q(X) \leq 1$. We have already argued that the presence of the short asset at date 1 requires $q(X) \leq 1$. We now show that $1 / \hat{R} \leq q(X)$. Seeking a contradiction, we suppose that $q(X)<1 / \hat{R}$. In this case, from the perspective of date 0 , investing in the short asset strictly dominates investing in the long asset. As a result, all agents invest only in the short asset at date 0 , resulting in $L^{R}=L^{U}=1$, and, according to (24), in $q(X)=\min \{\infty, 1\}=1$, a contradiction. It follows that $1 / \hat{R} \leq q(X) \leq 1$.

Next, we specialize the problem (A.13) for an unprotected agent as

$$
\max _{\ell \in[0,1]} \pi u(\ell e)+(1-\pi) \rho u\left(\hat{R}(1-\ell) e+\frac{\ell e}{q(X)}\right)
$$

The first-order condition is

$$
\psi(\ell) \equiv e \pi u^{\prime}(\ell e)-e(1-\pi)\left(\hat{R}-\frac{1}{q(X)}\right) \rho u^{\prime}\left(\hat{R}(1-\ell) e+\frac{\ell e}{q(X)}\right)=0 .
$$

Note that the agent's objective function is strictly concave in $\ell$, as $\psi^{\prime}(\cdot)<0$ for $\ell \in[0,1]$. Seeking a contradiction, suppose that $\ell=1$ is not optimal. It must thus be that $\psi(1)<0$, or $\pi u^{\prime}(e)<(1-\pi)\left(\hat{R}-\frac{1}{q(X)}\right) \rho u^{\prime}\left(\frac{e}{q(X)}\right) \leq(1-\pi)(\hat{R}-1) \rho u^{\prime}\left(\frac{e}{q(X)}\right) \leq(1-\pi)(\hat{R}-1) \rho u^{\prime}(e)$

which requires $\pi<\frac{\rho(R-1)}{1+\rho(R-1)}$. This contradicts Assumption (2). The solution to (A.14) must thus feature $\ell=1$.

Problem (A.13) specialized for a protected agent is given by

$$
\max _{\ell \in[0,1]} \pi u(\ell e+q(X) \hat{R}(1-\ell) e)+(1-\pi) \rho u\left(\hat{R}(1-\ell) e+\frac{\ell e}{q(X)}\right) .
$$

We distinguish two cases: $q(X)=1 / \hat{R}$ and $q(X)>1 / \hat{R}$. When $q(X)=1 / \hat{R}$, date 1 and 2 consumption does not depend on $\ell$, and therefore protected agents are then indifferent across all levels of $\ell \in[0,1]$. When $q(X)>1 / \hat{R}$, agents optimally choose $\ell=0$, since in that case the 
objective function is strictly decreasing in $\ell$.

Step 2 : Time-consistent equilibrium (as a function of $\gamma$ )

The investment decision of unprotected agents always leads to $\ell=L^{U}=1$. Regarding protected agents, we consider several cases. When $q=1 / \hat{R}$, protected agents are indifferent across any short-term investment level. Therefore, we can have $L^{P} \in[0,1]$, but consistency with the equilibrium price expression (24) requires

$$
L^{P}=\frac{\pi+\gamma-1}{\gamma}
$$

And since $L^{P} \geq 0$, this constellation only prevails when $\gamma \geq 1-\pi$. The equilibrium consumption allocations are then given by $c_{2}^{s}(0)=c_{1}^{s}(1)=0$ for $s \in\{U, P\}$ and

$$
c_{1}^{U}(0)=c_{2}^{P}(0)=e, \quad \text { and } \quad c_{2}^{U}(1)=c_{2}^{P}(1)=\hat{R} e .
$$

When $q>1 / \hat{R}$, protected agents' short asset decision at date 0 leads to $L^{P}=0$. Substituting $L^{P}=0$ and $L^{U}=1$ into the equilibrium price expression (24), we obtain

$$
q=\min \left\{\frac{1}{\hat{R}} \frac{1-\pi}{\pi} \frac{1-\gamma}{\gamma}, 1\right\} .
$$

Consistency thus requires $\gamma<1-\pi$, and the equilibrium consumption allocations are given by

$$
c_{1}^{U}(0)=e, \quad c_{2}^{U}(1)=\frac{1}{q} e, \quad c_{1}^{P}(0)=q \hat{R} e, \quad \text { and } \quad c_{2}^{P}(1)=\hat{R} e .
$$

\section{A.6 Proof of Proposition 4}

Let us define $\underline{\gamma} \equiv \frac{1-\pi}{1-\pi+\hat{R} \pi}$ and $\bar{\gamma} \equiv 1-\pi$. The government chooses $\gamma$ to maximize the average indirect utility function of private agents. It solves

$$
\mathcal{W}_{0}=\max _{\gamma \in[0,1]} \gamma \mathcal{V}_{0}\left(P,\left(\gamma, L^{P}(\gamma), 1\right)\right)+(1-\gamma) \mathcal{V}_{0}\left(U,\left(\gamma, L^{P}(\gamma), 1\right)\right)
$$

To characterize the solution to this problem, it is convenient to separately consider the optimal choice of $\gamma$ in the three intervals $[0, \underline{\gamma}],[\underline{\gamma}, \bar{\gamma}]$, and $[\bar{\gamma}, 1]$. We note that the objective function is continuous in $\gamma$.

First, for $\gamma \in[\bar{\gamma}, 1]$, the problem reduces to

$$
\max _{\gamma \in[\bar{\gamma}, 1]} \pi u(e)+(1-\pi) \rho u(\hat{R} e)
$$

The objective function is constant with respect to $\gamma$, and therefore any $\gamma \in[\bar{\gamma}, 1]$ is optimal. 
Next, for $\gamma \in[0, \underline{\gamma}]$, the problem is

$$
\max _{\gamma \in[0, \underline{\underline{\gamma}}]}[\pi+(1-\pi) \rho][\gamma u(\hat{R} e)+(1-\gamma) u(e)] .
$$

The objective function is strictly increasing in $\gamma$, so the optimal choice is given by $\gamma=\underline{\gamma}$.

Finally, for $\gamma \in[\underline{\gamma}, \bar{\gamma}]$, the problem is given by

$$
\max _{\gamma \in[\underline{\gamma}, \bar{\gamma}]} \gamma\left[\pi u\left(e \frac{1-\pi}{\pi} \frac{1-\gamma}{\gamma}\right)+(1-\pi) \rho u(\hat{R} e)\right]+(1-\gamma)\left[\pi u(e)+(1-\pi) \rho u\left(\hat{R} e \frac{\pi}{1-\pi} \frac{\gamma}{1-\gamma}\right)\right] .
$$

Since the overall objective function in (A.18) is strictly increasing over $[0, \gamma]$ and constant over $[\bar{\gamma}, 1]$, it must be that if (A.19) admits a strictly interior solution, then it will be the global solution of (A.18).

The first-order condition for problem (A.19) is

$$
\begin{aligned}
\phi(\gamma) \equiv & {\left[\pi u\left(e \frac{1-\pi}{\pi} \frac{1-\gamma}{\gamma}\right)+(1-\pi) \rho u(\hat{R} e)\right]-\left[\pi u(e)+(1-\pi) \rho u\left(\hat{R} e \frac{\pi}{1-\pi} \frac{\gamma}{1-\gamma}\right)\right] } \\
& -e \frac{1-\pi}{\gamma} u^{\prime}\left(e \frac{1-\pi}{\pi} \frac{1-\gamma}{\gamma}\right)+e \frac{\pi}{1-\gamma} \rho \hat{R} u^{\prime}\left(\hat{R} e \frac{\pi}{1-\pi} \frac{\gamma}{1-\gamma}\right) \lesseqgtr 0,
\end{aligned}
$$

with " $\leq$ " if $\gamma^{d}=\underline{\gamma}$, " $\geq$ " if $\gamma^{d}=\bar{\gamma}$, and " $=$ " if $\gamma^{d} \in(\underline{\gamma}, \bar{\gamma})$. Evaluating $\phi(\cdot)$ at the bounds $\underline{\gamma}$ and $\bar{\gamma}$, we have

$$
\begin{aligned}
& \phi(\underline{\gamma})=[\pi+(1-\pi) \rho][u(\hat{R} e)-u(e)]+e(1-\pi+\hat{R} \pi) \rho\left[u^{\prime}(e)-\rho^{-1} u^{\prime}(\hat{R} e)\right]>0, \\
& \phi(\bar{\gamma})=-e\left[u^{\prime}(e)-\rho \hat{R} u^{\prime}(\hat{R} e)\right]<0 .
\end{aligned}
$$

The global optimum is therefore strictly interior: $\gamma^{d} \in(\underline{\gamma}, \bar{\gamma})$.

\section{A.7 Proof of Proposition 5}

To establish how $\gamma^{d}$ changes with $\pi$ and $\hat{R}$, we use the implicit function theorem:

$$
\frac{\partial \gamma^{d}}{\partial x}=-\frac{\phi^{\prime}(x)}{\phi^{\prime}(\gamma)}, \quad \text { for } x \in\{\pi, \hat{R}\}
$$

First, we note that

$$
\phi^{\prime}(\gamma)=\frac{e^{2}(1-\pi)^{2}}{\pi \gamma^{3}} u^{\prime \prime}(q \hat{R} e)+\frac{e^{2} \pi^{2}}{(1-\pi)(1-\gamma)^{3}} \hat{R}^{2} \rho u^{\prime \prime}\left(\frac{e}{q}\right)<0 .
$$


The derivative of the implicit function $\phi(\cdot)$ with respect to $\pi$ is given by

$$
\begin{aligned}
\phi^{\prime}(\pi)= & {[u(q \hat{R} e)-u(e)]+e \frac{1}{\gamma}\left(1-\frac{1-\gamma}{\pi}\right) u^{\prime}(q \hat{R} e) } \\
& +\rho\left[u\left(\frac{e}{q}\right)-u(\hat{R} e)\right]+\rho \hat{R} e \frac{1}{1-\gamma}\left(1-\frac{\gamma}{1-\pi}\right) u^{\prime}\left(\frac{e}{q}\right) \\
& +e^{2} \frac{(1-\pi)(1-\gamma)}{\pi^{2} \gamma^{2}} u^{\prime \prime}(q \hat{R} e)+e^{2} \frac{\pi \gamma}{(1-\gamma)^{2}} \frac{1}{(1-\pi)^{2}} \rho \hat{R}^{2} u^{\prime \prime}\left(\frac{e}{q}\right) .
\end{aligned}
$$

Since $u(y)-u(z) \leq u^{\prime}(z)(y-z)$ for all $z \geq 0$ and $y \geq 0$ and $u^{\prime}(\hat{R} e) \leq u^{\prime}(e / q)$, we have

$$
\phi^{\prime}(\pi) \leq e^{2} \frac{(1-\pi)(1-\gamma)}{\pi^{2} \gamma^{2}} u^{\prime \prime}(q \hat{R} e)+e^{2} \frac{\pi \gamma}{(1-\gamma)^{2}} \frac{1}{(1-\pi)^{2}} \rho \hat{R}^{2} u^{\prime \prime}\left(\frac{e}{q}\right)<0
$$

and therefore

$$
\frac{\partial \gamma^{d}}{\partial \pi}=-\frac{\phi^{\prime}(\pi)}{\phi^{\prime}(\gamma)}<0
$$

The derivative of the implicit function $\phi(\cdot)$ with respect to $\hat{R}$ is given by

$$
\begin{aligned}
\phi^{\prime}(\hat{R}) & =\frac{1-\pi}{\hat{R}} \rho\left[\hat{R} e u^{\prime}(\hat{R} e)-\frac{e}{q} u^{\prime}\left(\frac{e}{q}\right)\right]+e \frac{\pi}{1-\gamma} \rho u^{\prime}\left(\frac{e}{q}\right)\left[u^{\prime}\left(\frac{e}{q}\right)+\frac{e}{q} u^{\prime \prime}\left(\frac{e}{q}\right)\right] \\
& =\frac{1-\pi}{\hat{R}} \rho\left[\int_{\frac{e}{q}}^{\hat{R} e} \frac{\partial}{\partial z}\left[z u^{\prime}(z)\right] d z\right]+e \frac{\pi}{1-\gamma} \rho u^{\prime}\left(\frac{e}{q}\right)\left[u^{\prime}\left(\frac{e}{q}\right)+\frac{e}{q} u^{\prime \prime}\left(\frac{e}{q}\right)\right] \\
& =\frac{1-\pi}{\hat{R}} \rho\left[\int_{\frac{e}{q}}^{\hat{R} e}\left[u^{\prime}(z)+z u^{\prime \prime}(z)\right] d z\right]+e \frac{\pi}{1-\gamma} \rho u^{\prime}\left(\frac{e}{q}\right)\left[u^{\prime}\left(\frac{e}{q}\right)+\frac{e}{q} u^{\prime \prime}\left(\frac{e}{q}\right)\right],
\end{aligned}
$$

where we note that the both terms in square brackets are necessarily non-positive by Assumption 1. It follows that $\phi^{\prime}(\hat{R}) \leq 0$, which in turn implies

$$
\frac{\partial \gamma^{d}}{\partial \hat{R}}=-\frac{\phi^{\prime}(\hat{R})}{\phi^{\prime}(\gamma)} \leq 0
$$

